\begin{tabular}{|c|l|}
\hline Title & Short-term glacier velocity changes at West Kunlun Shan, Northwest Tibet, detected by Synthetic A perture Radar data \\
\hline Author(s) & Y asuda, Takatoshi; Furuya, Masato \\
\hline Citation & $\begin{array}{l}\text { Remote Sensing of Environment, 128, 87-106 } \\
\text { https://doi.org/10.1016/.rse.2012.09.021 }\end{array}$ \\
\hline Issue Date & 2013-01-21 \\
\hline Doc URL & http://hdl.handle.net/2115/51782 \\
\hline Type & article(author version) \\
\hline File Information & RSE128_87-106.pdf \\
\hline
\end{tabular}

Instructions for use 


\title{
Short-term Glacier Velocity Changes at West Kunlun Shan, Northwest Tibet, Detected by Synthetic Aperture Radar Data
}

\author{
Takatoshi Yasuda and Masato Furuya \\ Department of Natural History Sciences, Graduate School of Science, Hokkaido \\ University, N10W8, Kita-ku, Sapporo 060-0810, JAPAN.
}

\begin{abstract}
Seasonal glacier velocity changes across the High Arctic, including the Greenland Ice Sheet, have been observed and have attracted significant attention over the past decade. However, it remains uncertain how much short-term variability exists in other polythermal glaciers, particularly those in High Asia. Here we report satellite radar image analyses that reveal diverse glacier surface velocities and their evolution in West Kunlun Shan (WKS), NW Tibet, where little is known about glacier dynamics. On the basis of radar images obtained from 2003 to 2011, we examined 36 glaciers, and classified them into two classes according to their multi-temporal velocity profiles: 25 as normal-flow type (surface velocity reaches maxima around the middle part, and gradually approaches zero toward downstream and upstream), and four as surging type (surface velocities are greater than $150 \mathrm{~m} / \mathrm{yr}$, and/or the terminus advance is recognized from the radar images). Seven other glaciers do not fit the former two classes, and reveal stagnant velocity profiles that are nearly zero in the lower part but are similar to those of the normal type in the upper part. Although these glaciers could be just stagnant tongues
\end{abstract}


indicative of receding normal type glaciers, given the temporal evolution at the Zhongfeng Glacier, the stagnant type possibly represents a quiescent phase of the surging type glaciers. While glacier surfaces are mostly clean with limited debris-cover, except near the termini, surge-type glaciers might be common in WKS. The observed short-term velocity changes provide us with evidence for efficient basal slip even at the high-elevation polythermal glaciers. This study demonstrates that frequent radar image acquisitions are helpful to understand short-term velocity changes at remote glaciers in detail.

Keywords: glacier velocity, West Kunlun Shan, surge, SAR, PALSAR

\section{Introduction}

Glacier surface velocity is a combination of the internal deformation of 3 the ice and basal slip, the latter of which consists of the basal sliding over 4 the bedrock and the deformation of the till overlying the bedrock [Cuffey 5 and Patterson, 2010]. As the speed associated with internal deformation can 6 possibly vary over long periods, short-term surface velocity variations can 7 be attributed to the basal slip due to reduction in the effective overburden

schadler, 1986]; by short-term we characterize velocity changes with timescale of less than a year. Such rapid signals detected over the past decade across the High Arctic, including the Greenland Ice Sheet, have been attracting considerable attention [e.g., Zwally et al., 2002; Rignot and Kanagaratnam, 2006;

Joughin et al., 2008; Bartholomaus et al., 2008; Sundal et al., 2011], not only because they were believed to be absent from cold glaciers, but also because 
surface melting in response to global warming could further accelerate glacier flow and potentially lead to significant loss of glacier mass [e.g., Zwally et al., 2002].

Due to the difficulty in directly monitoring glaciers in remote areas by fieldwork, satellite remote sensing techniques such as radar interferometry and pixel-offset tracking (or, feature/speckle tracking) of both optical and radar imaging have been used to detect glacier velocities [e.g., Joughin et al., 1996; Strozzi et al., 2002; Rignot and Kanagaratnam, 2006; Joughin et al., 2008; Sundal et al., 2011; Gourmelen et al., 2011]. Besides the glaciers in the High Arctic, these techniques have been applied to mountain glaciers in High Asia and elsewhere [e.g., Kääb, 2005; Luckman et al., 2007; Quincey et al., 2009, 2011; Scherler et al., 2011a, b; Mayer et al., 2011]. However, since the previous studies focused on secular to interannual changes, the temporal resolution was approximately a year. Thus, it remains unclear how much short-term variability exists in the glaciers in High Asia.

Although our initial aim was to study the Yutian earthquake (magnitude 7.1) on March 202008 in West Kunlun Shan (WKS, Figure 1) [Furuya and Yasuda, 2011], we accidentally detected significant glacier motion signals over a wide area in addition to the coseismic deformation signals. Because little is known about glacier dynamics in WKS, we began examining if the glaciers were moving irrespective of the earthquake. Using multitemporal surface velocity data from satellite-based radar imaging analysis, we found that the glaciers were actively moving irrespective of earthquakes, and that the glacier velocities unexpectedly exhibited a variety of spatial-temporal changes. The purpose of this paper is to report our observations of the 
surface velocity data in WKS with particular emphasis on the short-term variabilities such as seasonal change and surge. Whereas the WKS glaciers were considered cold-based glaciers, our observations indicate a variety of spatial and temporal surface velocity changes, including seasonality, surging, and quiescence. Moreover, we discuss the possible mechanisms for the shortterm variabilities.

\section{Study Area}

WKS is one of the highest regions in the world, and the main ridge varies between 6000 and $6500 \mathrm{~m}$ above sea level. Compared to the Hindu Kush, Karakoram, and Himalaya, the mean elevation of the glaciers in WKS is concentrated near $6000 \mathrm{~m}$, and the topographic relief is rather low [Scherler et al., 2011b]. Although it is a difficult area to access, following a reconnaissance in 1985, the China-Japan Joint Glaciological Expedition to WKS was executed in 1987 [Zheng et al., 1988]. The mean annual temperature and precipitation near the snow line $(5900 \mathrm{~m})$ on the northern slopes of these mountains were estimated to be $-14.7^{\circ} \mathrm{C}$ and $\sim 460 \mathrm{~mm}$, respectively [Zhang and Jiao, 1987]. Also, similar to the Himalaya [Ageta and Higuchi, 1984], most of the precipitation occurs in summer from June to August [Zhang and Jiao, 1987].

There are 278 glaciers along the main ridge of WKS with a total area of $2711.57 \mathrm{~km}^{2}$ [Shangguan et al., 2007], and they are assumed to be coldbased to polythermal (subpolar) glaciers. Scherler et al. [2011a] regarded the glaciers in WKS as the most continental setting in High Asia. Satellitebased remote sensing has been performed to examine temporal changes in 
the glaciated areas [Shangguan et al., 2007]; the total area loss observed between 1970 and 2001 is at most 0.4\%. On the basis of feature tracking of the Advanced Spaceborne Thermal Emission and Reflection Radiometer (ASTER) and Satellite Pour l'Observation de la Terre (SPOT) data, Scherler et al. [2011b] showed the surface velocities of several glaciers in WKS. However, these studies are based on optical imaging, and observation opportunities are limited due to cloud cover problems. Scherler et al. [2011a] also showed that the glaciers in West Kunlun Shan have limited debris cover.

\section{Data and Analysis Method}

\subsection{Satellite data}

To generate glacier surface velocity maps, we processed the Phased Arraytype L-band (wavelength of $23.6 \mathrm{~cm}$ ) Synthetic Aperture Radar (PALSAR) images from the Advanced Land Observation Satellite (ALOS) launched in 2006 by the Japan Aerospace Exploration Agency (JAXA) from February 2007 to February 2011 (Table 1, Figure 1); see Shimada et al. [2008] for details on the PALSAR. From 2003 to 2007, we also utilized the Advanced Synthetic Aperture Radar (ASAR) images from the Environmental Satellite (Envisat) launched in 2002 by the European Space Agency (Table 1, Figure 1). In comparison to an L-band sensor [Strozzi et al., 2008], the ASAR is a C-band (wavelength of $5.6 \mathrm{~cm}$ ) sensor that often suffers from decorrelation problems due to its shallower penetration depth into snow and ice [Rignot et al., 2001]. Nevertheless, we could extend the analysis period further to find how the surface velocity of a surging glacier evolved over time. The differences in the penetration depths by the different wavelengths will not 
affect the inferred velocities, because the most significant changes in the vertical velocity profile of glacier-flow are expected near the bed instead of near the surface [Cuffey and Patterson, 2010].

The PALSAR data cover the study area along two ascending paths 515 and 516 over the two tracks, frame 690 and 700 (Table 1, Figure 1). The off-nadir beam angle is $34.3^{\circ}$, which forms $\sim 38^{\circ}$ incident angle at the flat ground in the image center. There are two imaging modes Fine Beam Single polarization (FBS, HH) and Fine Beam Dual polarization (FBD; HH and $\mathrm{HV}$ ), respectively. We only used the $\mathrm{HH}$ polarization data. The difference between FBS and FBD is within the range (across track) resolution, which is $\sim 4.7 \mathrm{~m}$ for the FBS and $\sim 9.4 \mathrm{~m}$ for the FBD mode. The FBD data are oversampled twice along the range axis. On the other hand, the ASAR data used in this study were obtained along a descending path with a local incidence beam angle of $\sim 23^{\circ}$. The smaller incidence angle lowers the sensitivity to the east-west component of the displacement although it can raise that of the vertical component. The spatial resolution of ASAR in the range direction is almost the same as the FBD mode of PALSAR, which is half of the FBS mode.

\subsection{Surface velocity observations}

In this study, pixel-offset tracking (feature tracking or speckle tracking) algorithms are used to observe surface velocities, and these algorithms are based on maximizing the cross-correlation of the radar image patches [ Michel et al., 1999; Strozzi et al., 2002, 2008; Kobayashi et al., 2009]. We use the intensity tracking algorithm, because it is the only technique that can be applied in the study of fast-flowing glaciers with long data acquisition interval 
[Strozzi et al., 2002]. The method is also applicable to optical images. We employed a search patch of $\sim 300 \mathrm{~m}$ (range) $\times 600 \mathrm{~m}$ (azimuth) area on the ground with a sampling interval of $\sim 56 \mathrm{~m} \times 56 \mathrm{~m}$ on the ground. We set a signal-to-noise ratio (SNR) threshold of 5.0, and patches below this level were assigned to the missing data. Lower SNR data are presumably due to the large spatial separation length (baseline) of the repeating orbits (Bperp in Table 1) and/or temporal changes in the surface scattering characteristics; Bperp denotes the perpendicular component of the baseline projected onto the radar line of sight (LOS). Unfortunately, the Bperp for the PALSAR data pairs in summer was relatively long. Moreover, given the higher precipitation and temperature in summer, we can consider that snowfall and surface melting lowers the cross-correlation between the temporally separated image patches, and prevent us from deriving summer velocities particularly in the accumulation zones. Nonetheless, we emphasize that the surface velocity data detected along the glacier itself are robust when compared with the lack of significant changes outside the glaciated areas; we did not mask the non-glacier areas in the offset-tracking.

While performing pixel-offset tracking, we corrected the stereoscopic effect, which is shown as an artifact offset over rugged terrain [Michel et al., 1999; Kobayashi et al., 2009]. Because of the separation between satellite orbital paths, the effect of fore-shortening also differs in the offsets. Thus, we reduced the artifact by applying an elevation-dependent correction by employing the NASA's Shuttle Radar Topography Mission (SRTM-4) DEM data with a 3-arcsec resolution, in which the gaps in the original SRTM data were filled [Jarvis et al., 2008]. Note that the correction is different 
from the elimination of topographic phase in the differential interferometric phase measurement, and that the correction is unnecessary in the absence of significant topography. Although the SRTM data may include their own errors and are nearly a decade old, we used them because there were no gaps and apparent noises. Because there are no topography-correlated offsets, we consider that the stereoscopic correction is adequately performed, and it is unlikely that the errors in the SRTM DEM influenced our velocity data.

The pixel-offset tracking technique provides us with two displacement maps during the analyzed period; the range offset along the radar LOS and the azimuth offset along the satellite-track direction. $\mathrm{U}_{e}, \mathrm{U}_{n}$, and $\mathrm{U}_{z}$ were defined as eastward, northward, and upward positive displacements, respectively. The range offset is a projection of the 3D surface displacements onto the slant radar LOS direction, i.e., $0.62 \mathrm{U}_{e}+0.11 \mathrm{U}_{n}-0.78 \mathrm{U}_{z}$ for ALOS and $-0.38 \mathrm{U}_{e}+0.08 \mathrm{U}_{n}-0.92 \mathrm{U}_{z}$ for Envisat; the azimuth offset is a projection of the 3D surface displacements along the satellite-track direction, i.e., $-0.17 \mathrm{U}_{e}+0.99 \mathrm{U}_{n}$ for ALOS and $-0.21 \mathrm{U}_{e}-0.98 \mathrm{U}_{n}$ for Envisat. Therefore, the range offset is sensitive to both the east-west and vertical components, whereas the azimuth offset is most sensitive to the north-south component and shows no sensitivity to the vertical component. We derived the surface velocity data, following the parallel flow assumption [Joughin et al., 1996], although the assumption is not strictly met in reality. In this study, we used both the range and the azimuth offset components, so that the problem became over-determined and could be robustly solved by least-square methods. The local topographic gradient unit vector was estimated from a fore-mentioned SRTM-4 data. Although the elevation changes possibly 
occurred between the SRTM and the PALSAR/ASAR data acquisition are potential error sources, those changes would be insignificant for the computation of a unit vector, because only the local flow orientation and slope angles are necessary in the argument of trigonometric functions for the parallel flow approximation, and the ice thickness itself does not come into play.

The uncertainties of the offset measurements have been estimated to be $\sim 0.3-0.4 \mathrm{~m}$ at the rugged terrain on the basis of two data images with ALOS/PALSAR's 46-day intervals acquired at non-deforming areas [Kobayashi et al., 2009]. Assuming linear temporal evolution, the error in the velocity estimates can be inferred to be $2-4 \mathrm{~m} / \mathrm{yr}$. However, the errors in pixel-offset tracking can also arise from other sources. The longer the temporal separation, the smaller the errors in the velocity estimate, but the worse is the correlation between the image patches due to changes in the scattering properties of the objects. Thus, most of the data pairs shown in this study have the shortest possible 46-day and 35-day temporal separation, which denote the PALSAR and ASAR return periods, respectively.

\subsection{Detecting scattering intensity changes}

Besides the surface velocity data, radar images can directly estimate the extent of changes in glacier terminus locations if they are greater than several tens of meters. Furthermore, the RGB method is a simple and useful approach that can locate significant changes in the surface scattering intensities [Tobita et al., 2006]. Representing the older scattering intensity image with cyan $[($ Red, Green, Blue $)=(0 \%, 100 \%, 100 \%)$, Figure 2a], the newer intensity image with red [(Red, Green, Blue $)=(100 \%, 0 \%, 0 \%)$, Figure 2b] and adding the two images after co-registration, we can observe red/cyan 
areas where surface scattering intensities increase/decrease, and areas with no intensity changes remain gray (Figure 2c). Because we intentionally increased/decreased the intensity in the west/east part in Figure 2b, there arises an west-east gradient in the resulting Figure 2e. These two approaches are particularly useful to demonstrate glacier surge signals.

\section{Observation Results}

\subsection{Systematic examination and classification into two classes}

Figure 3 is a sample glacier surface velocity map in WKS overlaid on the PALSAR-based scattering intensity image. While the name of each glacier is based on the World Glacier Inventory and partly on Ma et al. [1989], each of the unnamed glaciers is merely numbered from the west to the east with a prefix, representing the side of the slope on which it exists, i.e., $\mathrm{N}$ for the northern and $\mathrm{S}$ for the southern slope. The velocities in Figure 3 are estimated from the pair of PALSAR images acquired on November 12 and December 30, 2008 for the western area (path 516), and the other pair of images acquired on December 12, 2008 and January 28, 2009 for the eastern area (path 515); see Table 1. As illustrated using a logarithmic scale, the surface velocities reveal a variety of magnitudes, ranging within two orders of magnitude (Figure 3). Although the available data do not cover all the glaciers uniformly in terms of both the spatial and temporal distributions, we examined systematically how the surface velocities varied in the 36 glaciers in Figure 3. Setting a centerline at each valley glacier from the terminus toward the up-glacier, we estimated the surface velocity profiles by averaging the data over a $500 \times 500 \mathrm{~m}^{2}$ area and regarded the standard deviations as the 
estimated errors. When the number of data samples was less than half of the total pixel numbers at each averaging area, or when the standard deviations were larger than $30 \mathrm{~m} / \mathrm{yr}$, we considered them as missing data.

Examining the spatial-temporal evolution of surface velocities in each glacier, we classify the 36 glaciers at WKS into normal-flow type, and surging type. We describe below each type of surface velocity data, and show a few typical examples; other glaciers' data, not shown here, are listed in the supplementary material. Seven of the examined glaciers, however, reveal stagnant profiles, and do not fit the two classes. Those stagnant velocity data and our interpretations on them are described in the Discussion.

\subsection{Normal Flow}

By a normal-flow type, we mean glaciers that continuously flow downstream without a stagnant zone, but exclude those with extremely rapid velocities greater than $150 \mathrm{~m} / \mathrm{yr}$, which are grouped into the surging type. Although it is not a commonly used threshold, the $150 \mathrm{~m} / \mathrm{yr}$ limit is chosen not only because other glaciers with similar slopes revealed much slower velocities, but also because the surging type glaciers exhibited terminus advance as well as significant intensity changes as shown below. Among the 36 examined glaciers, we classified 25 into the normal-flow category (Table 2 ). None of the 25 glaciers exhibited significant interannual surface velocity changes and terminus advances. Nonetheless, the magnitude of the surface velocities is highly variable, depending on each glacier. We begin by showing a few examples of the faster normal-flow glaciers.

Figures $4 \mathrm{a}$ and $4 \mathrm{~b}$ show the spatial-temporal evolution of the surface velocities and estimated errors, respectively, at the Duofeng Glacier, around 
which the adjacent ALOS satellite tracks overlap and allow further increase in the observation frequency. The Duofeng Glacier is the largest glacier in the WKS originating in the northern side of Liushi Shan (Kunlun Goddess, 7167 $\mathrm{m}$ above sea level), the highest peak in the WKS. The respective terminus and snowline altitudes are $4590 \mathrm{~m}$ and $5960 \mathrm{~m}$ above the sea level, and the mean depth estimated from the empirical relation between the glacier thickness and glacier area is $268 \mathrm{~m}$ [WGMS and NSIDC, 1989]. Although the inferred velocities in Figure 4a are largely consistent with those independently derived from optical images (see Figure 10c in Scherler et al., 2011b), the summer velocities are evidently faster than those during winter. Shown in Figure 4c are the velocity profiles averaged from winter and summer pairs. In addition, the elevation and local gradient profiles along the flow line are shown in Figure $4 \mathrm{~d}$. While the average winter velocities from October to February are $70 \pm$ $7 \mathrm{~m} / \mathrm{yr}$, those in summer from May to September are $92 \pm 10 \mathrm{~m} / \mathrm{yr}$. As shown in Figure 4c, however, the error bars are larger in summer, and the summer velocity data are missing in the upper part. A significant separation is found between 5 and $8 \mathrm{~km}$ from the terminus, where the summer and winter average speeds are $92 \mathrm{~m} / \mathrm{yr}$ and $64 \mathrm{~m} / \mathrm{yr}$, respectively.

Figures 5 and 6 show the results at the N3 Glacier and the eastern branch of the Kunlun Glacier, respectively; the mean depths of the N3 and Kunlun Glaciers are $194 \mathrm{~m}$ and $249 \mathrm{~m}$, respectively [WGMS and NSIDC, 1989]. Due to the large error bars particularly in summer, the summer speedup cannot be clearly recognized as observed at the Duofeng Glacier. We don't conclude, however, that summer speedup is absent in these glaciers. In Figures 4, 5 , and 6 , we could not derive a quality summer-velocity data particularly 
in the upper accumulation zone partly because of long Bperp and the surface scattering characteristics, which have changed significantly. In contrast, we confirmed that the radar scattering intensities in the lower part did not change appreciably, thereby aiding in the derivation of quality velocity data even in summer. This was probably because the rugged ice surfaces in the lower part could maintain intensity correlations with time; the rugged ice surfaces generate a higher radar-scattering intensity than the surfaces in the upper part, and they are also recognizable in the optical images of Google $\operatorname{Earth}^{T M}$.

The observed summer speedup signals are significant, because velocities above the winter average can be assumed to be due to basal sliding. The basal-slip enhancement in summer can reach a maxima of $\sim 30 \mathrm{~m} / \mathrm{yr}$ between 5 and $8 \mathrm{~km}$ from the terminus of the Duofeng Glacier. Because the time scale of the internal deformation variability is much longer than those of summer speedup events, the $\sim 40 \%$ surface-velocity increase is unlikely due to the increase in deformation velocity.

Most of the normal-flow glaciers, however, reveal slower winter velocities than those in Figures 4, 5, and 6, despite the similar elevation profiles and mean depths. Shown in Figures 7 and 8 are the results for the Yulong Glacier and the eastern branch of the Kunlun Glacier, respectively; the mean depth of Yulong is $223 \mathrm{~m}$ [WGMS and NSIDC, 1989]. Moreover, although there appears to be a summer speedup near the terminus region in the eastern branch of the Kunlun Glacier (Figure 8a and 8c), summer-velocity data are missing, and the seasonalities remain uncertain in Figures 7 and 8. The missing data for the summer in the slower glaciers is due to not only the 
temporal changes in surface scattering characteristics but also the absence of rugged surfaces, as found in the faster glaciers in Figures 4, 5, and 6, thereby preventing the preservation of intensity correlations in summer.

\subsection{Surging type}

Using Envisat/ASAR radar images to extend the analysis period and further analyze temporal changes in the radar intensities as well as the terminus locations, we identify four glaciers as the surging type. The most compelling evidence for surging was derived from the westernmost tributary of the Zhongfeng Glacier in the southern slope. Moreover, we consider that three extremely rapid glaciers in Figure 3, the West Kunlun, N2, and N7 Glaciers, are undergoing surge. Although Scherler et al. [2011b] mentioned that stagnant glacier fronts were "most likely" due to past surges, they did not show velocity data during the surge in WKS. On the basis of temporal evolution of the velocity profile at the Zhongfeng Glacier's westernmost tributary, it turns out that surging is followed by stagnant flow near the terminus. This is the first observation report of a glacier surge in WKS, to the best of our knowledge. Although the upper part of the surge-type glaciers certainly appears white, and it is difficult to tell any looped or folded moraines, we could recognize medial moraines in the Zhongfeng, N2, and West Kunlun Glaciers from the optical images available on Google $\operatorname{Earth}^{T M}$. These observations could also corroborate the surging nature of the glaciers.

Figures 9 show spatial-temporal changes in the surface velocities and related data for the westernmost tributary of the Zhongfeng Glacier. Although it is uncertain when exactly the surge initiated and terminated, Figure 9a illustrates that the surface velocities exceeded $1000 \mathrm{~m} / \mathrm{yr}$ over the wide area 
along the glacier at least for half a year from 2004 to 2005, followed by a slow down in 2006. Since 2007, the surface-velocity data indicate the stagnant flow, in which almost all the lower half of the entire glacier has virtually stopped, whereas the upper half moves. We observed that after the peak of the surging phase, the surface velocities gradually decreased from $\sim 100 \mathrm{~m} / \mathrm{yr}$ in 2007 to $\sim 30 \mathrm{~m} / \mathrm{yr}$ in 2010 . The temporal duration of the slowdown phase spans $\sim 3$ years, which is much longer than that after the 1982-1983 surge at the Variegated Glacier [Kamb et al., 1985]. The detected spatial-temporal evolution in the surface-velocity data presumably indicates a dynamic evolution in the basal environment.

Next, we show the significant scattering intensity changes that could be interpreted as quiescent changes in the surface roughness. Representing the images acquired on February 9, 2007 and February 20, 2011 with cyan and red, respectively, we derive a composite image in Figure 10. Because the original two images were obtained on similar seasons, we may neglect seasonal effects such as snow-fall and surface melting. Figure 10 shows an apparent decrease in the scattering intensity at the surging tributary, whereas the other tributaries to the east remained nearly the same. The period in Figure 10 is a quiescent phase, when the surface velocities became gradually slower (Figure 9a). Because the scattering intensity generally decreases as the scattering surface becomes smoother, our interpretation of intensity reduction is that the rugged surfaces generated by the preceding surge are gradually recovering to their original smoother forms by, for instance, a closure of crevasses and/or cracks. Although this interpretation needs to be verified by other independent observations, we elucidate another example that indicates drastic 
increase in the scattering intensity, which can be associated with an ongoing surge.

Figures 11 and 12 show the results for the West Kunlun and the N2 Glaciers, respectively; the result for the N7 Glacier is in the supplementary materials. The velocities at these two glaciers were as high as 170-200 m/yr from November 2008 to February 2009 (Figure 11a and 12a). Although they are slower than the peak velocities at the Zhongfeng Glacier shown in Figure 9, these are much faster than the adjacent western tributary of the West Kunlun Glacier, whose maximum speed is $\sim 20 \mathrm{~m} / \mathrm{yr}$ despite the similar elevation and slope profiles in all three glaciers. Also, as observed at the surge-type glaciers in Karakoram [Quincey et al., 2011], the velocities reach maximum values near the lowermost part at the two glaciers. At the N2 Glacier (Figure 12), the peak surface velocities from late 2008 to 2009 were preceded by an acceleration phase at least from 2007 to 2008, which is again similar to the findings of surge-type glaciers in Karakoram [Quincey et al., 2011].

Moreover, we identified a rapid advance in the termini initiated around late 2008 - early 2009 (Figure 13) by visually tracking the terminus locations in the intensity images. None of the other non-surging glaciers exhibited significant advances in the terminus location. We recorded the amount of advance, and found that the N2 Glacier advanced by $105 \mathrm{~m}$ from August to October 2009. Although the most rapid advance ceased in 2009, the surging continued until the end of the study period. The exact timing of the initiation and termination of the surge remains uncertain, but the temporal duration seems to be at least longer than half a year at the N2 Glacier. Figure 11 
also suggest years' long surge duration at the West Kunlun Glacier. To place stricter constraints, however, we need to extend the analysis period further.

Figure 14 is a composite image derived via the RGB method, using the images same as those in Figure 10; it reveals red-colored areas in the West Kunlun and N2 Glaciers, indicating recent drastic increases in the scattering intensities. This is contrary to the case in Figure 10, probably indicating that the surface became more rugged due to the drastic increase in the crevasses/cracks associated with surging.

\section{Discussion}

\subsection{Stagnant flow}

Seven glaciers were not classified into either normal or surging type (Table 2 ), because they reveal very small surface velocities near the lower part of the glacier but active motion in the upper part. Figures 15, 16, and 17 show the surface velocities and related data for the Chongce, West Yulong, and the second branch of the Zhongfeng Glacier, respectively. Summer speedup signals were not as significant as we could recognize in Figure 4. We could not find any significant changes in both the terminus locations and scattering intensities, either.

In analogy with the velocity evolution at the westernmost tributary of the Zhongfeng Glacier (Figure 9), the stagnant glaciers may represent a quiescent phase of surge cycles. Also, the longitudinal velocity profiles are consistent with the well-known thermal structure of polythermal surging glaciers at Bakaninbreen and Monacobreen, Svalbard [Murray et al., 1998, 2000, 2003] and Trapridge Glacier, Yukon, Canada [Clarke et al., 1984; Frappé 
and Clarke, 2007]. The downstream resistance due to thermal structure appears to be a common factor. Although the glaciers in WKS have not been considered as the surge type, and terminus elevations are higher than those observed in the central Karakoram [Hewitt, 2007], implying a much colder climate, these observations indicate that glacier surges in WKS could be common and widely distributed, suggesting that nearly one third of the examined 36 glaciers could be of the surge type.

However, it is also possible that the observed velocity distributions may simply represent stagnant tongues of receding normal glaciers, because if the terminus region is actually very thin and gently sloping, slow terminal zones are possible. Long-term velocity observations are necessary to answer if each stagnant glacier is normal type or surging type. However, the observed surface gradients in panel (d) of Figures 15-17 are not particularly low, when compared with those for other studied glaciers. We thus consider that those are likely to be surge-type glaciers in quiescence.

The basal temperature was recorded to be $-2.1^{\circ} \mathrm{C}$ at a depth of $\sim 300 \mathrm{~m}$ at the Guliya Icecap (over $6000 \mathrm{~m}$ above sea level, Figure 1), where $\sim 300 \mathrm{~m}$ ice-core data have been sampled in the early 1990s [Thompson et al., 1995]. To the best our knowledge, no other basal temperature data are available for the remaining glaciers in WKS, and, in fact, they could be near the melting point. The thermal structure of these glaciers needs to be examined to understand the glacier dynamics in WKS better.

\subsection{Possible Surging Mechanisms in WKS}

A dynamic evolution of the subglacial hydrological system has been suggested to explain rapid velocity changes [e.g., Kavanaugh and Clarke, 2001; 
Mair et al., 2003; Bartholomaus et al., 2008; Schoof, 2010] and glacier surge [e.g., Clarke et al., 1984; Kamb, 1987]. Regarding the physics of surging, the extent of influence of the deformation of subglacial till on the disruptions of subglacial hydrological systems has also been discussed [Truffer et al., 2000; Harrison and Post, 2003].

Although water storage is essential to control any surging event, it remains unclear whether there is sufficient volume of meltwater supply, because sublimation is more important than melting for ablation mechanism under the cold and arid environment of WKS [Ageta et al., 1989]. While the overall retreat of glaciers in WKS shown by Scherler et al. [2011a] may suggest increased surface melt due to long-term climate change, our observations indicate that not all the glaciers reveal short-term velocity changes. Although Clarke et al. [1986] concluded that it was not a likely mechanism for surging, a thermal triggering mechanism that does not require surface meltwater has been proposed to result in the surge in polythermal glaciers [e.g., Clarke, 1976]. The cold environment can help develop a relatively thick ice that could thermally insulate its basal layer, which can start melting because of the overburden pressure and/or geothermal heat flux and will form a subglacial hydrological system to control the initiation and termination of the surge [Clarke et al., 1976; Fowler et al., 2001]. Clarke et al. [1984], however, did not find evidence for trapped water increasing the pore pressure. Instead, they suggested a reduction in the discharging capacity associated with the deformation of the permeable substrate. The WKS area is tectonically active not only as exemplified by the 2008 Yutian earthquake [Furuya and Yasuda, 2011] but also by the Kunlun volcano group located $\sim 30 \mathrm{~km}$ to the 
northeast, where the latest eruption was witnessed in 1951, and 70 volcanic cones are well-preserved [Liu and Maimaiti, 1989; Siebert and Simkin, 2002]. These geological settings are consistent with the previous findings that surging glaciers occur in tectonically active mountain ranges, whose glacier beds tend to be deformable sediment [Cuffey and Patterson, 2010]. As the basal till emerges near the terminus in WKS [Zheng et al., 1989], till deformation may also be related to the surging events [e.g., Truffer et al., 2000]. Moreover, although it is speculative, the elevated geothermal heat flux cannot be ignored as a possible cause for meltwater generation.

We can recall that in WKS, the glaciers are almost debris free and with clean ice [Zheng et al., 1989; Scherler et al., 2011a]. Although glacier surges have often been reported in debris-rich glaciers [Harrison and Post, 2003; Barrand and Murray, 2006], our observations of surges in WKS suggest that the debris cover is not an indispensable attribute for surge-type glaciers, and that surging events on clean glaciers may have gone unnoticed. Nonetheless, although the upper part of the surging glaciers certainly appears white, we can recognize the debris-rich ice near the terminus as well as medial and terminal moraines in the Zhongfeng, N2, and West Kunlun Glaciers from the optical images available on Google Earth ${ }^{T M}$, consistent with the field observation report by Zheng et al. [1989]. It is likely that they were generated from basal erosion during previous surges. Quincey et al. [2011] reported two surge type glaciers with clean ice in Karakoram, and related the findings to a possible recent tendency of the Karakoram surges to be controlled by thermal rather than hydrological conditions. Whereas surges on clean-ice glaciers were unknown in Karakoram, our observations in WKS suggest that 
surges on mostly clean-ice glaciers could be common.

\section{Conclusions}

By applying the pixel-offset tracking (feature tracking) technique to SAR images, we examined spatial and temporal variabilities in the surface velocity of 36 glaciers in WKS. Although the WKS glaciers have been assumed to be mostly cold-based because of the cold, arid environment at high elevation, we found clear summer speedup signals in nine glaciers as well as surging signals in four glaciers. These short-term surface velocity changes provide us with the evidence for effective basal slip in WKS. Given the velocity evolution data for the Zhongfeng Glacier, the stagnant glaciers may represent a quiescent phase, although they could be simply normal glaciers with thiner and gently sloping terminal zones.

\section{Acknowledgement}

PALSAR level 1.0 data in this study were provided by the PALSAR Interferometry Consortium to Study our Evolving Land surface (PIXEL) and the ALOS 3rd PI project under cooperative research contracts with the JAXA. The ownership of PALSAR data belongs to JAXA and the Ministry of Economy, Trade and Industry. Envisat data are copyrighted by ESA and were provided under Cat-1 project 7344 . We thank S. Sugiyama and R. S. Anderson for reading an earlier draft, and also thank two anonymous reviewers for their constructive comments. We acknowledge the ESPEC Foundation for Global Environment Research and Technology for supporting this study. This study is partially supported by KAKENHI (24651001). 


\section{References}

Ageta, Y., \& K. Higuchi. (1984). Estimation of mass balance components of a summer-accumulation type glacier in the Nepal Himalaya, Geogr. Ann. Ser. A, Phys. Geogr., 66, 249-255, http://dx.doi.org/10.2307/520698.

Ageta, Y., W. Zhang, \& M. Nakawo. (1989). Mass balance studies on Chongce Ice Cap in the West Kunlun Mountains, Bull. Glacier Res., 7, $37-43$.

Bartholomaus, T. C., R. S. Anderson, \& S. P. Anderson. (2008). Response of glacier basal motion to transient water storage, Nat. Geosci., 1, 33-37, http://dx.doi.org/ 10.1038/ngeo.2007.52.

Barrand, N. E., \& T. Murray. (2006). Multivariate controls on the incidence of glacier surging in the Karakoram Himalaya, Arct. Antarct. Alp. Res., 38(4), 489-498, http://dx.doi.org/10.1657/15230430(2006)38[489:MCOTIO]2.0.CO;2.

Clarke, G. K. C. (1976). Thermal regulation of glacier surging, J. Glaciol., $16,231-250$.

Clarke, G. K. C., S. G. Collins, \& D. E. Thomson. (1984). Flow, thermal structure, and subglacial conditions of a surge-type glacier, Can. J. Earth Sci., 21(2), 232-240.

Clarke, G. K. C., J. P. Schmok, C. M. L. Ommanney, \& S. G. Collins. (1986). Characteristics of Surge-Type Glaciers, J. Geophys. Res., 91(B7), $7165-7180$. 
Cuffey, K. M., \& W. S. B. Paterson. (2010). The Physics of Glaciers, 4th ed., Elsevier.

Frappé, T.-P., \& G. K. C. Clarke. (2007). Slow surge of Trapridge Glacier, Yukon Territory, Canada, J. Geophys. Res., 112, F03S32, http://dx.doi.org/10.1029/2006JF000607.

Fowler, A. C., T. Murray, \& F. S. L. Ng. (2001). Thermally controlled glacier surging, J. Glaciol., 47, 527-538.

Furuya, M., \& T. Yasuda. (2011). The 2008 Yutian normal faulting earthquake (Mw 7.1), NW Tibet: Non-planar fault modeling and implications for the Karakax Fault, Tectonophys., 511, 125-133, http://dx.doi.org/10.1016/j.tecto.2011.09.003.

Gourmelen, N., S. W. Kim, A. Shepherd, J. W. Park, A. V. Sundal, H. Björnsson, \& F. Pálsson. (2011). Ice velocity determined using conventional and multiple-aperture InSAR, Earth Planet. Sci. Lett., 307, 156-160, http://dx.doi.org/10.1016/j.epsl.2011.04.026.

Harrison, W. D., \& A. S. Post. (2003). How much do we really know about glacier surging?, Ann. Glaciol., 36, 1-6.

Hewitt, K. (2007). Tributary glacier surges: an exceptional concentration at Panmah Glacier, Karakoram Himalaya, J. Glaciol., 53(181), 181-188.

Iken, A., \& R. A. Bindschadler. (1986). Combined measurements of subglacial water pressures and surface velocity of the Findelengletscher, Switzerland. Conclusions about drainage systems and sliding mechanism, J. Glaciol., 32, 101-119. 
Jarvis A., H. I. Reuter, A. Nelson, \& E. Guevara. (2008). Hole-filled seamless SRTM data V4, International Centre for Tropical Agriculture (CIAT), available from http://srtm.csi.cgiar.org.

Joughin, I., R. Kwok, \& M. Fahnestock. (1996). Estimation of ice-sheet motion using satellite radar interferometry: Method and error analysis with application to Humboldt Glacier, Greenland, J. Glaciol., 42, 564-575.

Joughin, I., S. B. Das, M. A. King, B. E. Smith, I. M. Howat, \& T. Moon. (2008). Seasonal speedup along the western flank of the Greenland ice sheet, Science, 320, 781-783, http://dx.doi.org/ 10.1126/science.1153288.

Kavanaugh, J. L., \& G. K. C. Clarke. (2001). Abrupt glacier motion and reorganization of basal shear stress following the establishment of a connected drainage system, J. Glaciol., 47, 472-480.

Kääb, A. (2005). Combination of SRTM3 and repeat ASTER data for deriving alpine glacier flow velocities in the Bhutan Himalaya, Remote Sens. Environ., 94, 463-474, http://dx.doi.org/10.1016/j.rse.2004.11.003.

Kamb, B., C. F. Raymond, W. D. Harrison, H. Engelhardt, K. A. Echelmeyer, N. Humphrey, M. M. Brugman, \& T. Pfeffer. (1985). Glacier surge mechanism: 1982-1983 surge of Variegated Glacier, Alaska, Science, 227, 469-479.

Kamb, B. (1987). Glacier surge mechanism based on linked cavity configuration of the basal water conduit system, J. Geophys. Res., 92, 9083-9100.

Kobayashi, T., T. Takada, M. Furuya, \& M. Murakami. (2009). Locations and types of ruptures involved in the 2008 Sichuan earthquake 
inferred from SAR image matching, Geophys. Res. Lett., 36, L07302, http://dx.doi.org/10.1029/2008GL036907.

Liu, J., \& Y. Maimaiti. (1989). Distribution and ages of Ashikule volcanoes on the West Kunlun Mountains, west China, Bull. Glacier Res., 7, 187-190.

Luckman, A., D. J. Quincey, \& S. Bevan. (2007). The potential of satellite radar interferometry and feature tracking for monitoring flow rates of Himalayan glaciers, Remote Sens. Environ., 111(2-3), 172-181.

Ma, Q., B. Zheng, K. Jiao, S. Iwata, \& H. Fushimi. (1989). Glacial geomorphological features in upper reaches of Yurunkax River on the north slope of the West Kunlun Mountains, Bull. Glacier Res., 7, 139-144.

Mair, D., I. Willis, U. H. Fischer, B. Hubbard, P. Nienow, \& A. Hubbard. (2003). Hydrological controls on patterns of surface, internal and basal motion during three 'spring events': Haut Glacier d'Arolla, Switzerland, J. Glaciol., 49, 555-567.

Mayer, C., A. C. Fowler, A. Lambrecht, \& K. Scharrer. (2011). A surge of North Gasherbrum Glacier, Karakoram, China. J. Glaciol., 57(204), 904916.

Michel, R., J.-P. Avouac, \& J. Taboury. (1999). Measuring ground displacements from SAR amplitude images: Application to the Landers Earthquake, Geophys. Res. Lett., 26, 875-878.

Murray, T., J. A. Dowdeswell, D. J. Drewry, \& I. Frearson. (1998). Geometric evolution and ice dynamics during a surge of Bakaninbreen, Svalbard, J. Glaciol., 44, 263-272. 
Murray, T., G. W. Stuart, P. J. Miller, J. Woodward, A. M. Smith, P. R. Porter, \& H. Jiskoot. (2000). Glacier surge propagation by thermal evolution at the bed, J. Geophys. Res., 105(B6), 13491-13507.

Murray, T., T. Strozzi, A. Luckman, H. Jiskoot, \& P. Christakos. (2003). Is there a single surge mechanism? Contrasts in dynamics between glacier surges in Svalbard and other regions, J. Geophys. Res., 108(B5), 2237, http://dx.doi.org/10.1029/2002JB001906.

Quincey, D. J., L. Copland, C. Mayer, M. Bishop, A. Luckman, \& M. Beló. (2009). Ice velocity and climate variations for Baltoro Glacier, Pakistan, J. Glaciol., 55, 1061-1071, http://dx.doi.org/ 10.3189/002214309790794913.

Quincey, D. J., M. Braun, N. F. Glasser, M. P. Bishop, K. Hewitt, \& A. Luckman. (2011). Karakoram glacier surge dynamics, Geophys. Res. Lett., 38, L18504, http://dx.doi.org/10.1029/2011GL049004.

Rignot, E., K. Echelmeyer, \& W. Krabill. (2001). Penetration depth of interferometric syntheticaperture radar signals in snow and ice, Geophys. Res. Lett., 28(18), 3501-3504.

Rignot, E. and P. Kanagaratnam. (2006). Changes in the velocity structure of the Greenland ice sheet, Science, 311, 986-990, http://dx.doi.org/ $10.1126 /$ science. 1121381.

Scherler, D., B. Bookhagen, \& M. R. Strecker. (2011a). Spatially variable response of Himalayan glaciers to climate change affected by debris cover, Nat. Geosci., 4, 156-159, http://dx.doi.org/10.1038/ngeo1068. 
Scherler, D., B. Bookhagen, \& M. R. Strecker. (2011b). Hillslope-glacier coupling: The interplay of topography and glacial dynamics in High Asia, J. Geophys. Res., 116, F02019, http://dx.doi.org/10.1029/2010JF001751.

Schoof, C. (2010). Ice-sheet acceleration driven by melt supply variability, Nature, 468, 803-806, http://dx.doi.org/ 10.1038/nature09618.

Shangguan, D., S. Liu, Y. Ding, J. Li, Y. Zhang, L. Ding, X. Wang, C. Xie, \& G. Li. (2007). Glacier changes in the west Kunlun Shan from 1970 to 2001 derived from Landsat TM/ETM+ and Chinese glacier inventory data, Ann. Glaciol., 46, 204-208, http://dx.doi.org/ 10.3189/172756407782871693.

Shimada, M., Y. Fukushima, T. Ozawa, M. Furuya, \& A. Rosenqvist. (2008). Japanese L-band radar improves surface deformation monitoring, EOS, Trans. Am. Geophys. Union, 89 (31), 277-278.

Siebert, L., \& T. Simkin. (2002-). Volcanoes of the World: an Illustrated Catalog of Holocene Volcanoes and their Eruptions. Smithsonian Institution, Global Volcanism Program Digital Information Series, GVP-3, (http://www.volcano.si.edu/world/). Last accessed on August 2012.

Strozzi, T., A. Luckman, T. Murray, U. Wegmüller, \& C. L. Werner. (2002). Glacier motion estimation using satellite-radar offset-tracking procedures, IEEE. Trans. Geosci. Remote Sens., 40(11), 2834-2391.

Strozzi, T., A. Kouraev, A. Wiesmann, U. Wegmüller, A. Sharov, \& C. L. Werner. (2008). Estimation of Arctic glacier motion with satellite L-band SAR data, Remote Sens. Environ., 112, 636-645. 
Sundal, A. V., A. Shepherd, P. Niemow, E. Hanna, S. Palmer, \& P. Huybrechts. (2011). Melt-induced speed-up of Greenland ice sheet offset by efficient subglacial drainage, Nature, 469, 521-524, http://dx.doi.org/ 10.1038/nature09740.

Thompson, L. G., E. Mosley-Thompson, M. E. Davis, P. N. Lin, J. Dai, \& J. F. Bolzan. (1995). A 1000 year climatic ice-core record from the Guliya ice cap, China: its relationship to global climate variability, Ann. Glaciol., 21, $175-181$.

Tobita, M., H. Suito, T. Imakiire, M. Kato, S. Fujiwara, \& M. Murakami. (2006). Outline of vertical displacement of the 2004 and 2005 Sumatra earthquakes revealed by satellite radar imagery, Earth Planets Space, 58, e1-e4. Truffer, M., W. D. Harrison, \& K. A. Echelmeyer. (2000). Glacier motion dominated by processes deep in underlying till, J. Glaciol., 46, 213-221.

WGMS and NSIDC. (1989). updated 2012. World Glacier Inventory. Compiled and made available by the World Glacier Monitoring Service, Zurich, Switzerland, and the National Snow and Ice Data Center, Boulder CO, U.S.A. http://dx.doi.org/ 10.7265/N5/NSIDC-WGI-2012-02.

Zhang, Z., \& K. Jiao. (1987). Modern glaciers on the south slope of West Kunlun Mountains (in Aksayqin Lake and Guozha Co Lake drainage areas), Bull. Glacier Res., 5, 85-91.

Zheng, B., H. Fushimi, K. Jiao, \& S. Li. (1989). Characteristics of basal till and the discovery of tephra layers in the West Kunlun Mountains, Bull. Glacier Res., 7, 177-186. 
${ }_{642}$ Zheng, B., J. Chen, \& Y. Ageta. (1988). The preliminary report of Sino${ }_{643}$ Japanese Joint Glaciological Expedition in the West Kunlun Mountains ${ }_{644}$ 1987, Bull. Glacier Res., 6, 75-80.

${ }_{645}$ Zwally, H. J., W. Abdalati, T. Herring, K. Larson, J. Saba, \& K. Stef646 fen. (2002). Surface melt-induced acceleration of Greenland ice-sheet flow, 647 Science, 297, 218-222, http://dx.doi.org/ 10.1126/science.1072708. 
Table 1: Details of the processed image pairs

\begin{tabular}{|c|c|c|c|c|c|c|c|c|}
\hline Sensor/Path & Pair \# & Master & Slave & Mode & $\operatorname{Bperp}(\mathrm{m})^{a}$ & $\operatorname{Span}(\mathrm{d})^{b}$ & Mean $\mathrm{SNR}^{c}$ & $\%$ of pixel ${ }^{d}$ \\
\hline \multirow{11}{*}{ PALSAR $/ 515^{e}$} & 1 & $09 / 10 / 2007$ & $12 / 11 / 2007$ & FBD-FBS & -619.6 & 92 & 7.5 & 76.1 \\
\hline & 2 & $12 / 11 / 2007$ & $01 / 26 / 2008$ & FBS-FBS & -284.2 & 46 & 14.6 & 90.5 \\
\hline & 3 & $01 / 26 / 2008$ & $04 / 27 / 2008$ & FBS-FBD & -1196.8 & 92 & 9.1 & 83.6 \\
\hline & 4 & $04 / 27 / 2008$ & $06 / 12 / 2008$ & FBD-FBD & 7080.5 & 46 & 6.2 & 40.6 \\
\hline & 5 & $06 / 12 / 2008$ & $07 / 28 / 2008$ & FBD-FBD & -3734.3 & 46 & 6.6 & 45.4 \\
\hline & 6 & $07 / 28 / 2008$ & $12 / 13 / 2008$ & FBD-FBS & 1141.2 & 138 & 7.3 & 74.3 \\
\hline & 7 & $12 / 13 / 2008$ & $01 / 28 / 2009$ & FBS-FBS & -261.8 & 46 & 14.8 & 91.6 \\
\hline & 8 & $01 / 28 / 2009$ & $06 / 15 / 2009$ & FBS-FBD & -659.9 & 138 & 7.0 & 73.9 \\
\hline & 9 & $06 / 15 / 2009$ & $12 / 16 / 2009$ & FBD-FBS & -1013.3 & 184 & 7.1 & 77.8 \\
\hline & 10 & $12 / 16 / 2009$ & $01 / 31 / 2010$ & FBS-FBS & -531.8 & 46 & 15.7 & 92.0 \\
\hline & 11 & $01 / 31 / 2010$ & $02 / 03 / 2011$ & FBS-FBS & -1772.6 & 368 & 10.5 & 91.1 \\
\hline \multirow{13}{*}{$\mathrm{PALSAR} / 516^{e}$} & 12 & $02 / 09 / 2007$ & $08 / 12 / 2007$ & FBS-FBD & -747.7 & 184 & 6.8 & 80.0 \\
\hline & 13 & 08/12/2007 & $09 / 27 / 2007$ & FBD-FBD & -162.5 & 46 & 8.3 & 72.1 \\
\hline & 14 & $09 / 27 / 2007$ & $12 / 28 / 2007$ & FBD-FBS & -340.9 & 92 & 8.5 & 89.0 \\
\hline & 15 & $12 / 28 / 2007$ & $05 / 14 / 2008$ & FBS-FBD & -1464.3 & 138 & 7.9 & 87.8 \\
\hline & 16 & $05 / 14 / 2008$ & $06 / 29 / 2008$ & FBD-FBD & 2819.0 & 46 & 6.6 & 48.2 \\
\hline & 17 & $06 / 29 / 2008$ & $09 / 29 / 2008$ & FBD-FBD & 1646.4 & 92 & 6.9 & 67.2 \\
\hline & 18 & $09 / 29 / 2008$ & $11 / 14 / 2008$ & FBD-FBS & -380.7 & 46 & 9.2 & 83.3 \\
\hline & 19 & $11 / 14 / 2008$ & $12 / 30 / 2008$ & FBS-FBS & 1.3 & 46 & 15.2 & 97.3 \\
\hline & 20 & $12 / 30 / 2008$ & 02/14/2009 & FBS-FBS & 710.3 & 46 & 14.6 & 96.7 \\
\hline & 21 & 02/14/2009 & 08/17/2009 & FBS-FBD & -397.8 & 184 & 7.7 & 79.0 \\
\hline & 22 & 08/17/2009 & $10 / 02 / 2009$ & FBD-FBD & -502.3 & 46 & 10.0 & 74.1 \\
\hline & 23 & 10/02/2009 & $01 / 02 / 2010$ & FBD-FBS & -585.9 & 92 & 9.2 & 92.5 \\
\hline & 24 & $01 / 02 / 2010$ & $02 / 20 / 2011$ & FBS-FBS & -2605.9 & 414 & 9.2 & 87.9 \\
\hline \multirow{5}{*}{ ASAR $/ 248^{f}$} & 25 & $11 / 07 / 2003$ & $12 / 12 / 2003$ & IS2 & 283.7 & 35 & 9.0 & 49.4 \\
\hline & 26 & $09 / 17 / 2004$ & $10 / 22 / 2004$ & IS2 & 38.9 & 35 & 9.5 & 70.3 \\
\hline & 27 & $03 / 11 / 2005$ & $04 / 15 / 2005$ & IS2 & -62.7 & 35 & 8.9 & 64.8 \\
\hline & 28 & $01 / 20 / 2006$ & $03 / 31 / 2006$ & IS2 & 17.9 & 70 & 8.7 & 74.2 \\
\hline & 29 & $03 / 16 / 2007$ & $04 / 20 / 2007$ & IS2 & -386.4 & 35 & 7.2 & 53.5 \\
\hline
\end{tabular}




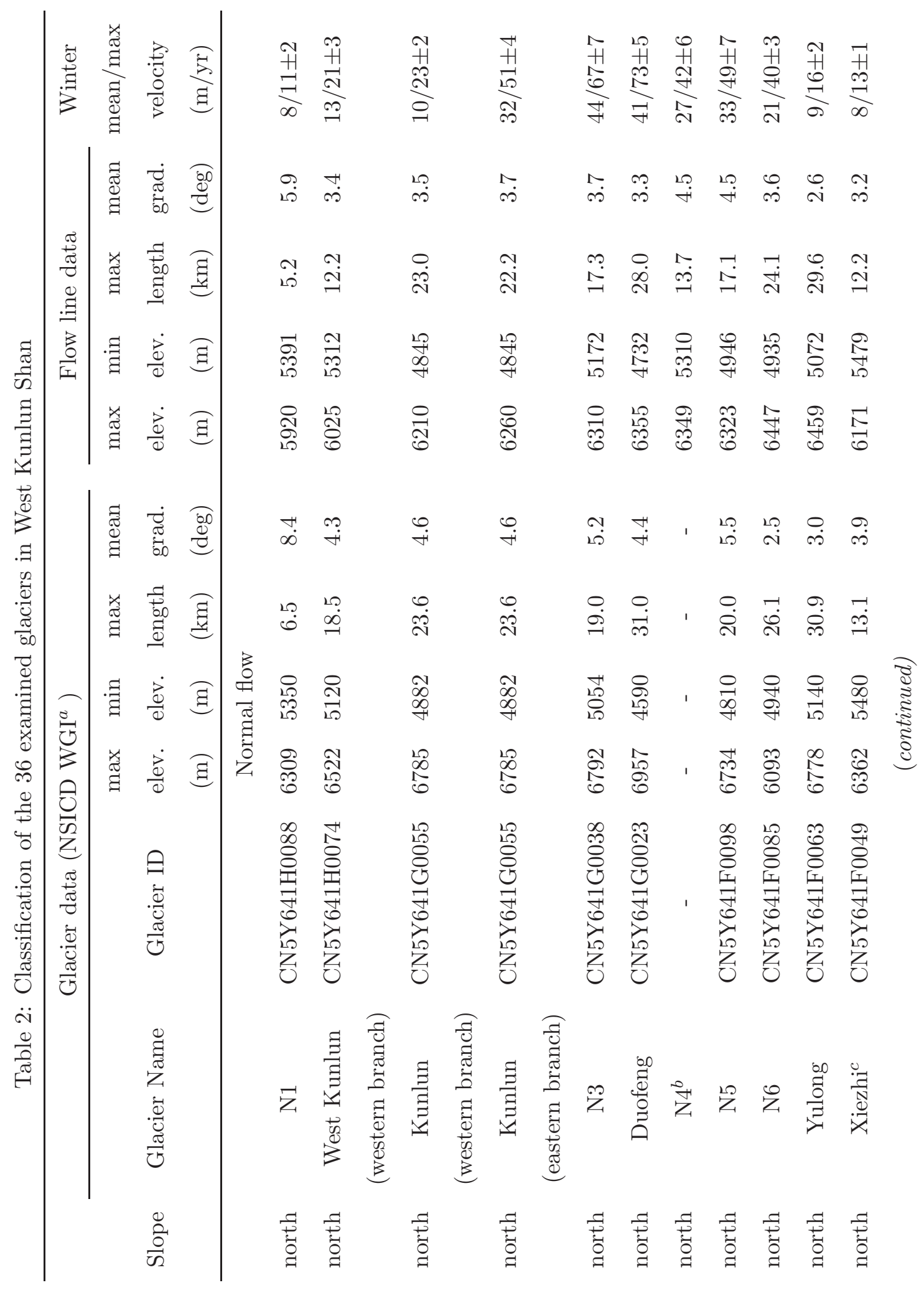




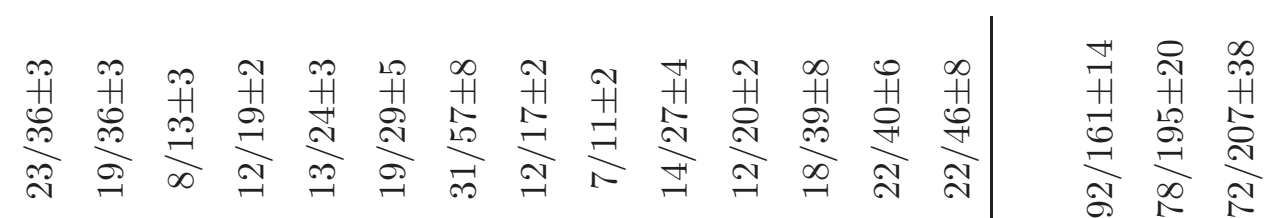

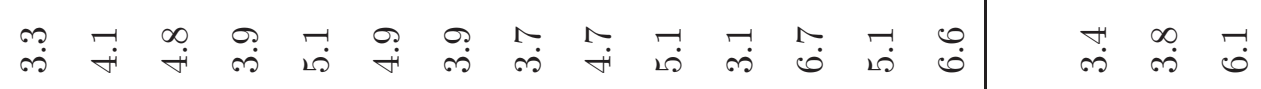

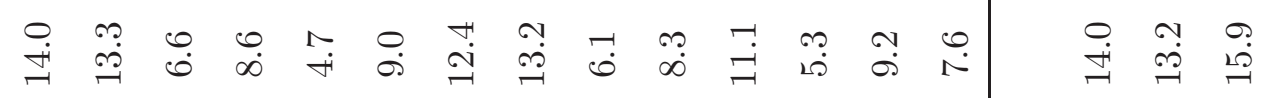

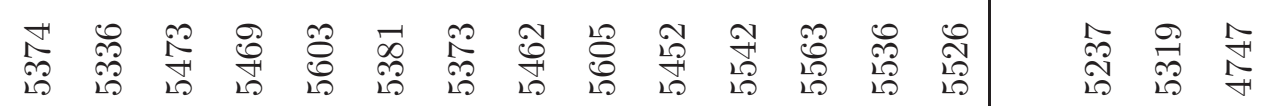

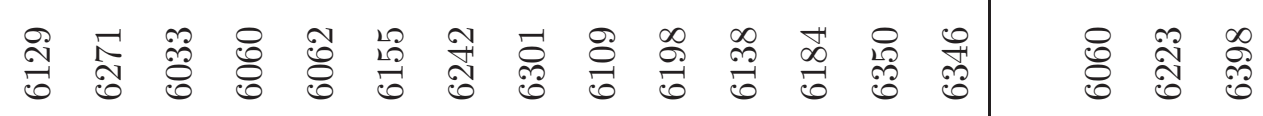

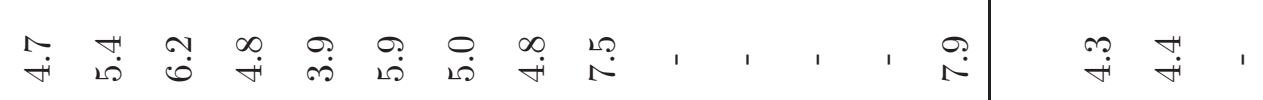

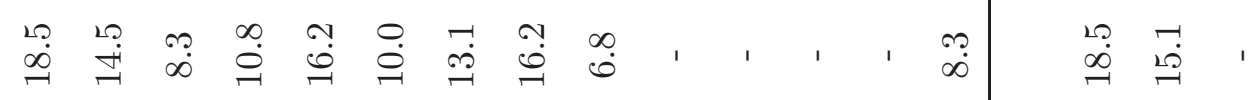

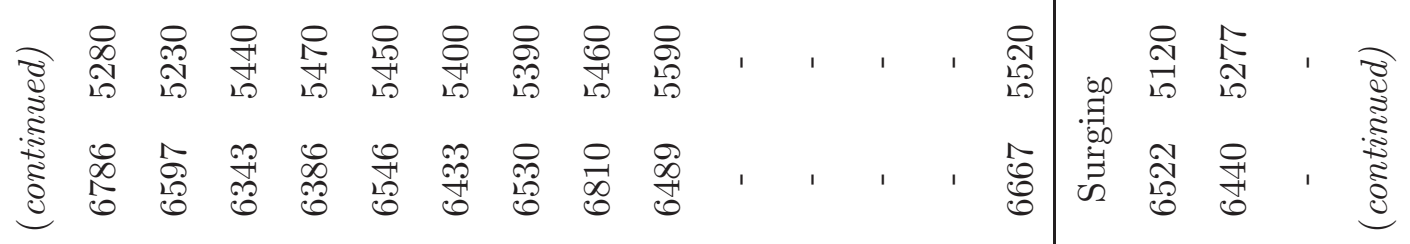

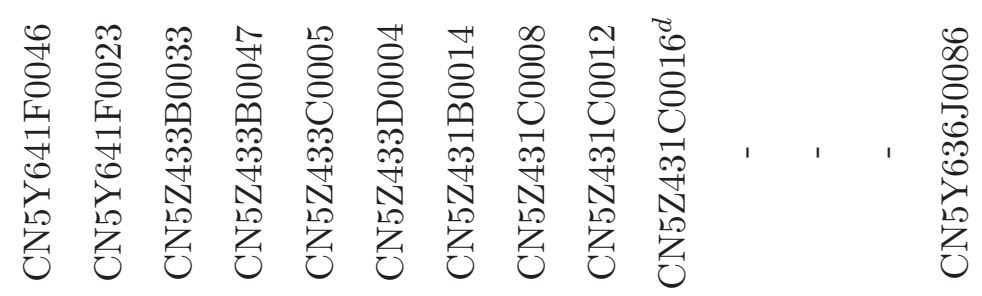

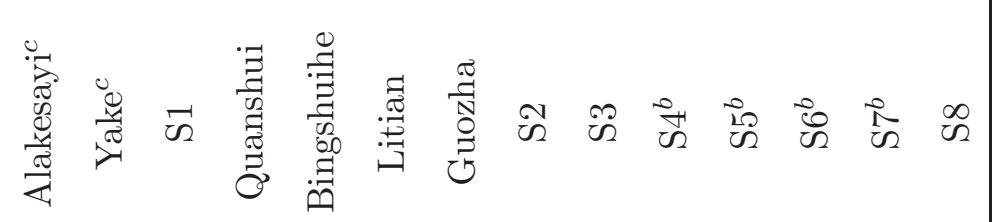

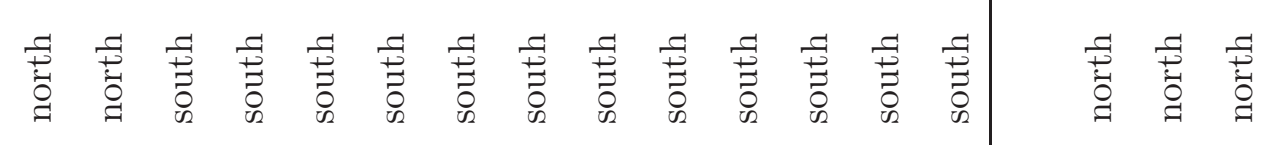




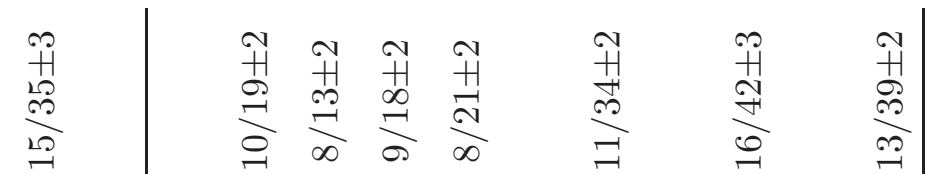

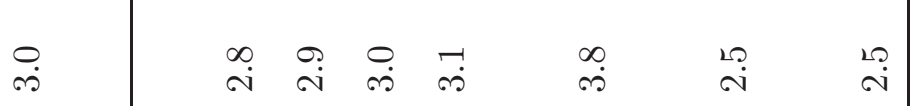

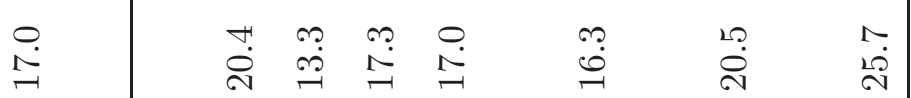

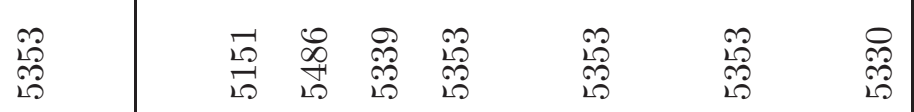

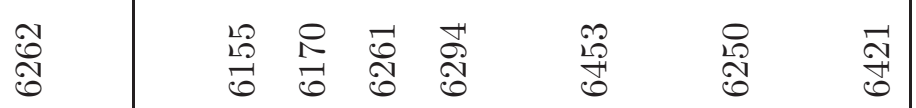

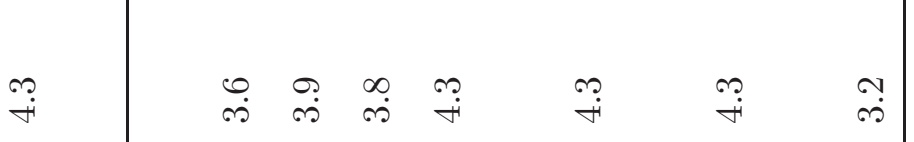

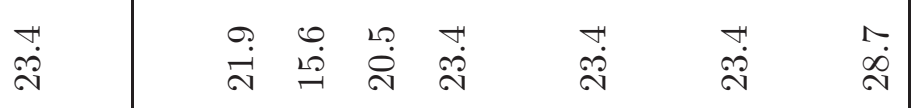

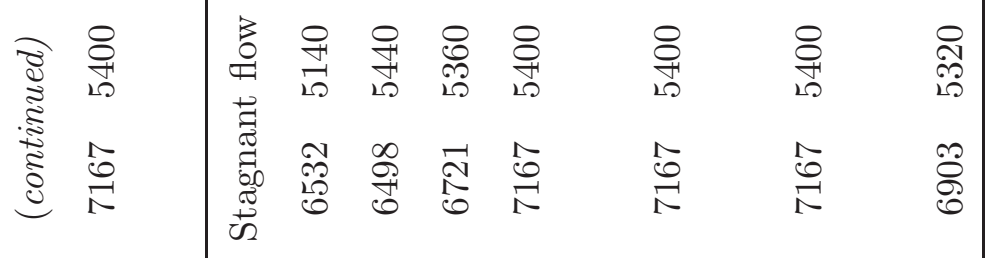

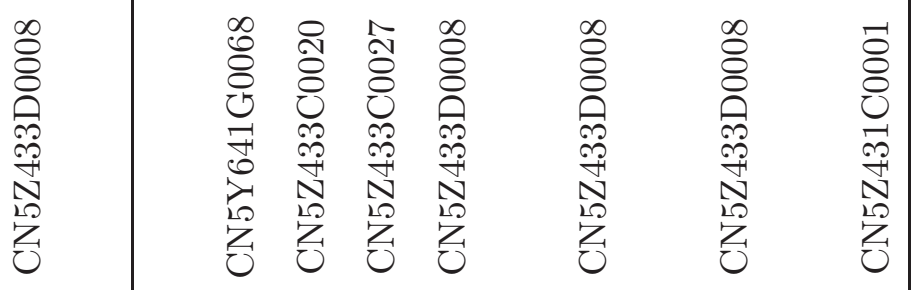

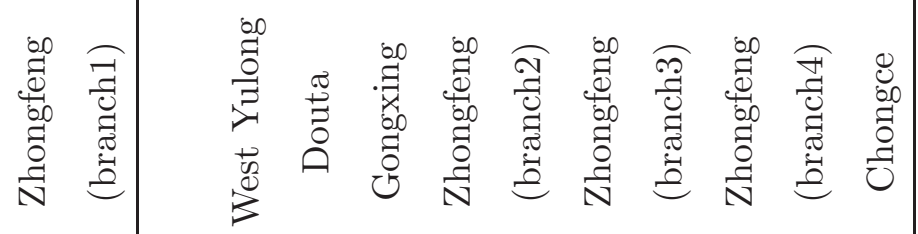

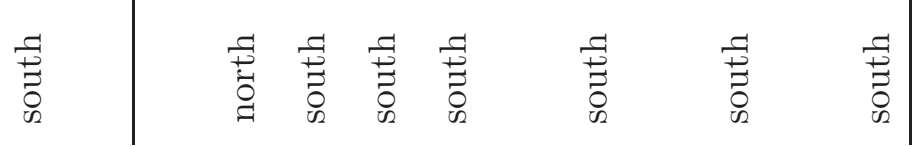


Table 1: a: Orbit separation distance perpendicular to the radar line-of-sight. b: Temporal separation. c: Lower SNR less than 5.0 was rejected. d: Percentage of accepted pixels. e: Ascending track of ALOS/PALSAR. f: Descending track of Envisat/ASAR.

Table 2: Classification of the 36 examined glaciers in West Kunlun Shan. a: NSIDC world glacier inverntory (http://nsidc.org/data/glacier_inventory), b: No data are available from WGI, c: Ma et al [1989], d: Zheng et al [1989]

Figure 1: Study area and ALOS/PALSAR (path 515 and 516) and Envisat ASAR (path 248) data coverage in this study; see Table 1. Inset shows the location of the Tibetan plateau and the analyzed area.

Figure 2: Principle of the RGB (Red, Green, and Blue) method. (a) Old radar scattering intensity image. (b) New intensity image. (c) Old intensity image marked with cyan. (d) Newer intensity image marked with red. (e) Composite image after the RGB addition of the intensity images (c) and (d). While the red/cyan areas show where the surface scattering intensities have increased/decreased, areas that underwent no intensity changes remain gray.

Figure 3: A sample glacier surface velocity map at West Kunlun Shan overlaid on the PALSAR-based scattering intensity image. Note that the scale is logarithmic. The velocity estimates are derived from November 12, 2008 to December 30, 2008 for the western area (path 516) and from December 12, 2008 to January 28, 2009 for the eastern area (path 515); see Table 1. The examined glacier names and the Guliya icecap are indicated. Thin black lines denote flow lines, and magenta lines are the divides in the middle. 
Figure 4: Surface velocity evolution at the Duofeng Glacier. (a) Spatial-temporal evolution of the surface velocities recorded from 2003 to 2011. (b) Error estimates of (a). (c) Average velocity profiles for summer (red) and winter (blue). The 'x' symbols are the values used in the computation of the summer and winter average. (d) The elevation and local gradient profiles along the chosen flow line.

Figure 5: Surface velocity evolution at the N3 Glacier. (a) Spatial-temporal evolution of the surface velocities recorded from 2003 to 2011. (b) Error estimates of (a). (c) Average velocity profiles for summer (red) and winter (blue). The 'x' symbols are the values used in the computation of the summer and winter average. (d) The elevation and local gradient profiles along the chosen flow line.

Figure 6: Surface velocity evolution at the western branch of the Kunlun Glacier. (a) Spatial-temporal evolution of the surface velocities recorded from 2003 to 2011. (b) Error estimates of (a). (c) Average velocity profiles for summer (red) and winter (blue). The 'x' symbols are the values used in the computation of the summer and winter average. (d) The elevation and local gradient profiles along the chosen flow line.

Figure 7: Surface velocity evolution at the Yulong Glacier. (a) Spatial-temporal evolution of the surface velocities recorded from 2003 to 2011. (b) Error estimates of (a). (c) Average velocity profiles for summer (red) and winter (blue). The 'x' symbols are the values used in the computation of the summer and winter average. (d) The elevation and local gradient profiles along the chosen flow line.

Figure 8: Surface velocity evolution at the eastern branch of the Kunlun Glacier. (a) Spatial-temporal evolution of the surface velocities recorded from 2003 to 2011. (b) Error estimates of (a). (c) Average velocity profiles for summer (red) and winter (blue). The 'x' symbols are the values used in the computation of the summer and winter average. (d) The elevation and local gradient profiles along the chosen flow line. 
Figure 9: Surface velocity evolution at the westernmost tributary of Zhongfeng Glacier. (a) Spatial-temporal evolution of the surface velocities recorded from 2003 to 2011. (b) Error estimates of (a). (c) Average velocity profiles for summer (red) and winter (blue). The ' $x$ ' symbols are the values used in the computation of the summer and winter average. (d) The elevation and local gradient profiles along the chosen flow line.

Figure 10: RGB composite intensity image of an old image obtained on February 9, 2007 and a new image obtained on February 20, 2011. Cyan-colored area indicates a reduction in the scattering intensity.

Figure 11: Surface velocity evolution at the West Kunlun Glacier. (a) Spatial-temporal evolution of the surface velocities recorded from 2003 to 2011. (b) Error estimates of (a). (c) Average velocity profiles for summer (red) and winter (blue). The 'x' symbols are the values used in the computation of the summer and winter average. (d) The elevation and local gradient profiles along the chosen flow line.

Figure 12: Surface velocity evolution at the N2 Glacier. (a) Spatial-temporal evolution of the surface velocities recorded from 2003 to 2011. (b) Error estimates of (a). (c) Average velocity profiles for summer (red) and winter (blue). The ' $x$ ' symbols are the values used in the computation of the summer and winter average. (d) The elevation and local gradient profiles along the chosen flow line. 
Figure 13: Terminus advances at the West Kunlun and N2 Glaciers recorded from ALOS/PALSAR intensity images.

Figure 14: RGB composite intensity image of an old image obtained on February 9, 2007 and a new image obtained on February 20, 2011. Red-colored area indicates an increase in the scattering intensity.

Figure 15: Surface velocity evolution at the Chongce Glacier. (a) Spatial-temporal evolution of the surface velocities recorded from 2003 to 2011. (b) Error estimates of (a). (c) Average velocity profiles for summer (red) and winter (blue). The 'x' symbols are the values used in the computation of the summer and winter average. (d) The elevation and local gradient profiles along the chosen flow line.

Figure 16: Surface velocity evolution at the West Yulong Glacier. (a) Spatial-temporal evolution of the surface velocities recorded from 2003 to 2011. (b) Error estimates of (a). (c) Average velocity profiles for summer (red) and winter (blue). The 'x' symbols are the values used in the computation of the summer and winter average. (d) The elevation and local gradient profiles along the chosen flow line.

Figure 17: Surface velocity evolution at the second branch of the Zhongfeng Glacier. (a) Spatial-temporal evolution of the surface velocities recorded from 2003 to 2011. (b) Error estimates of (a). (c) Average velocity profiles for summer (red) and winter (blue). The 'x' symbols are the values used in the computation of the summer and winter average. (d) The elevation and local gradient profiles along the chosen flow line. 


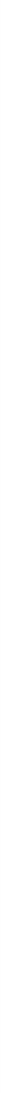


Master SAR intensity image
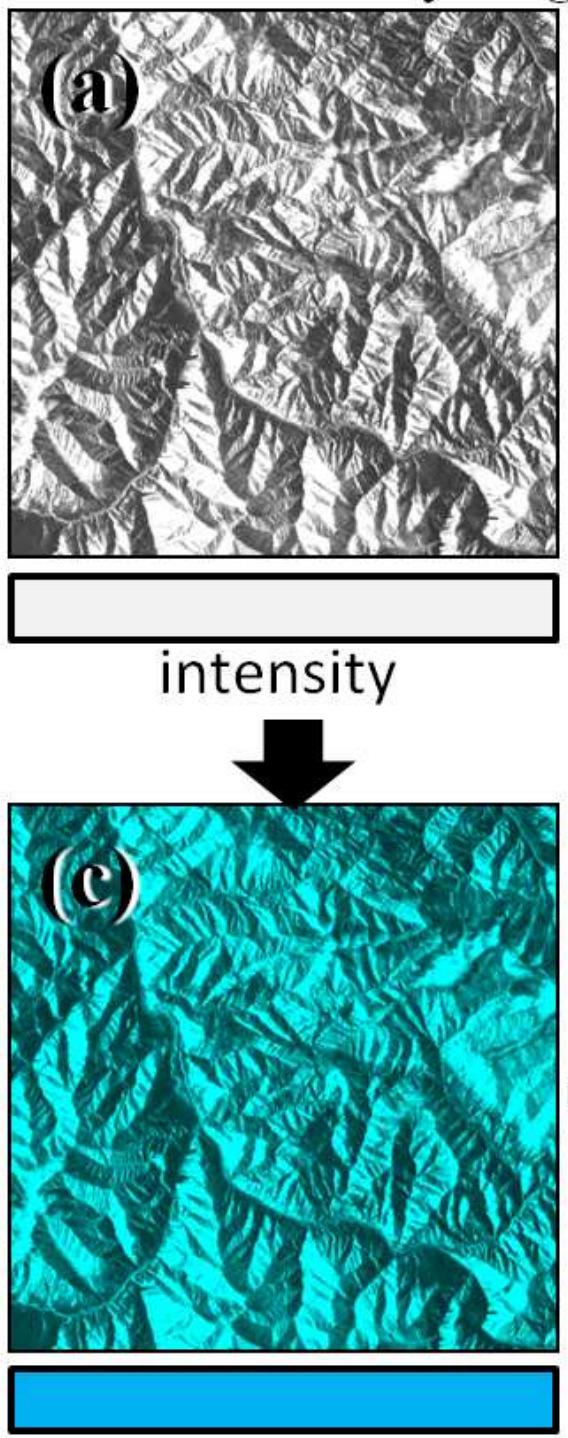

intensity

$(\mathbf{R}, \mathbf{G}, \mathbf{B})=(\mathbf{0}$, Master, Master $)$
Slave SAR intensity image
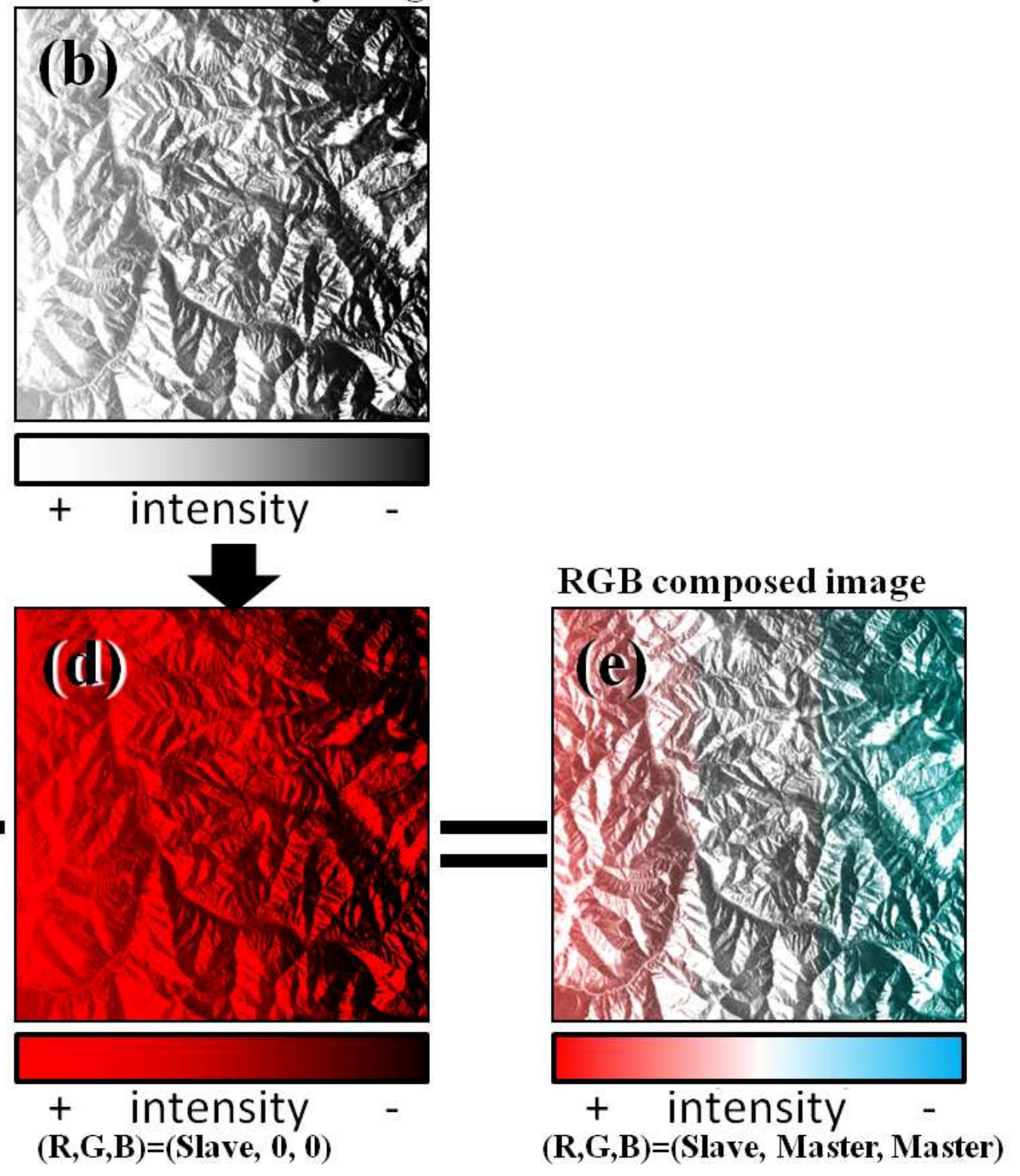


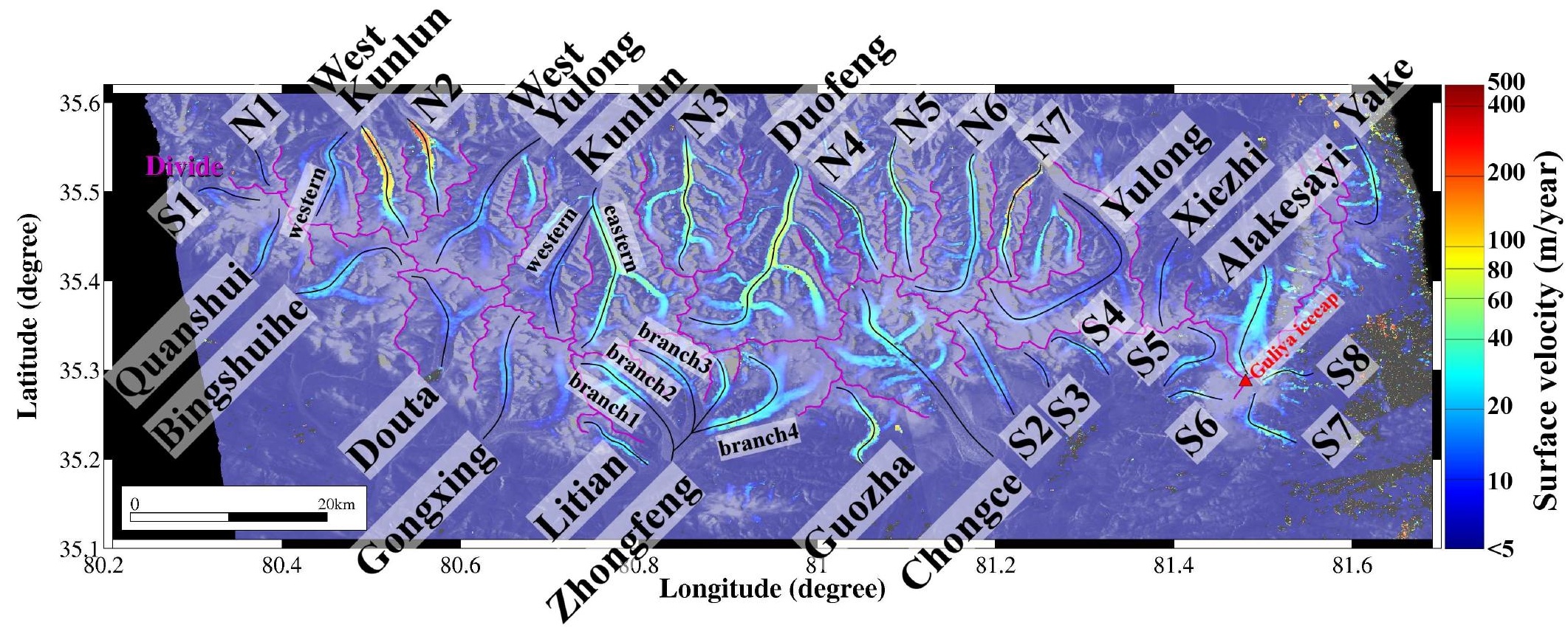


Figure 4

(a)
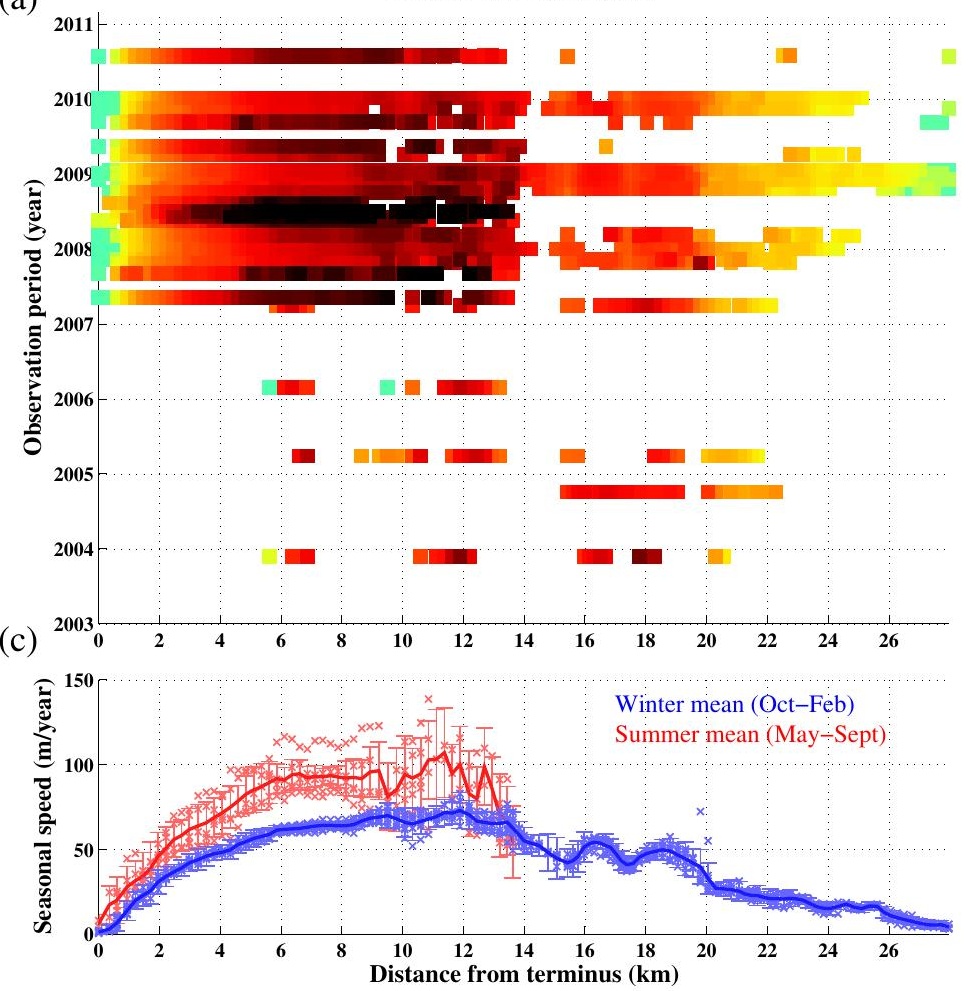

(b)
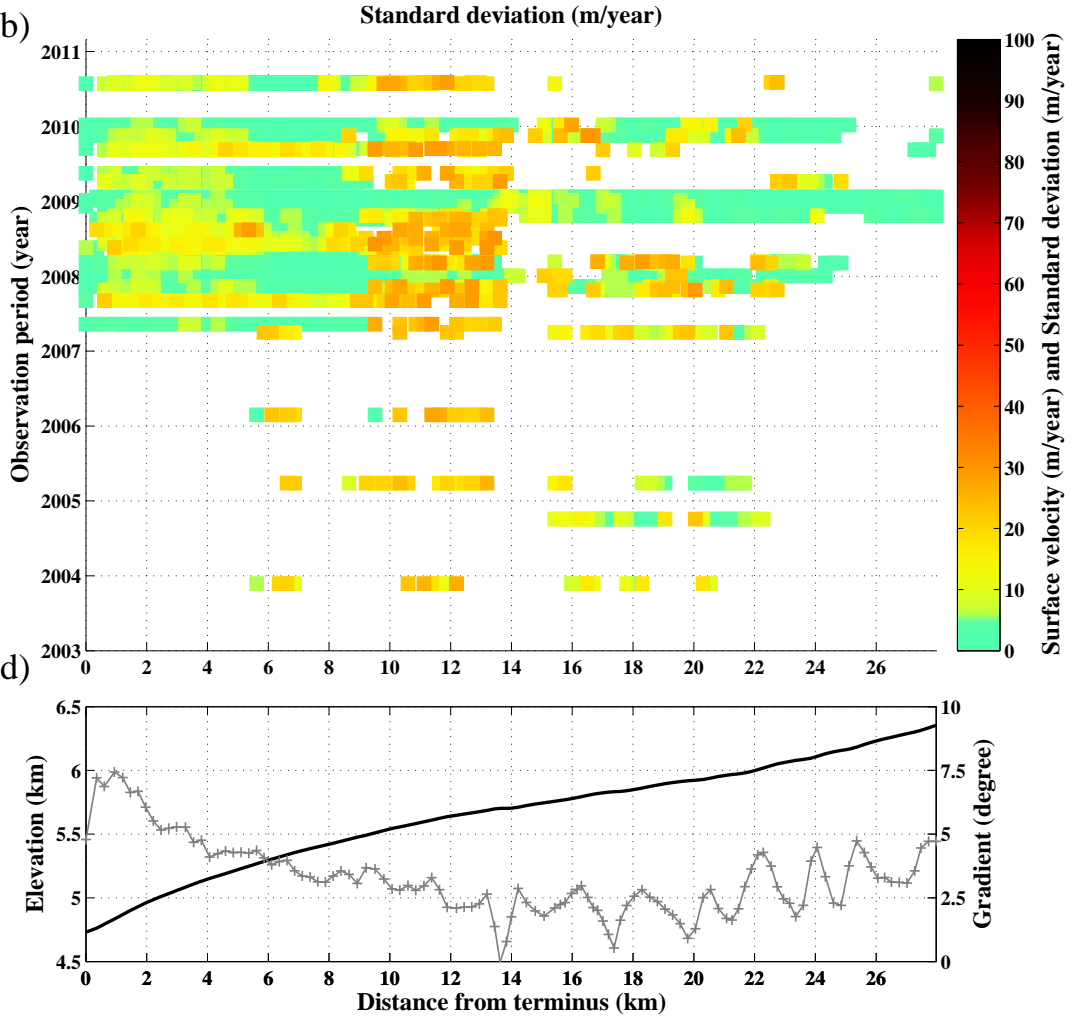
Figure 5

(a)
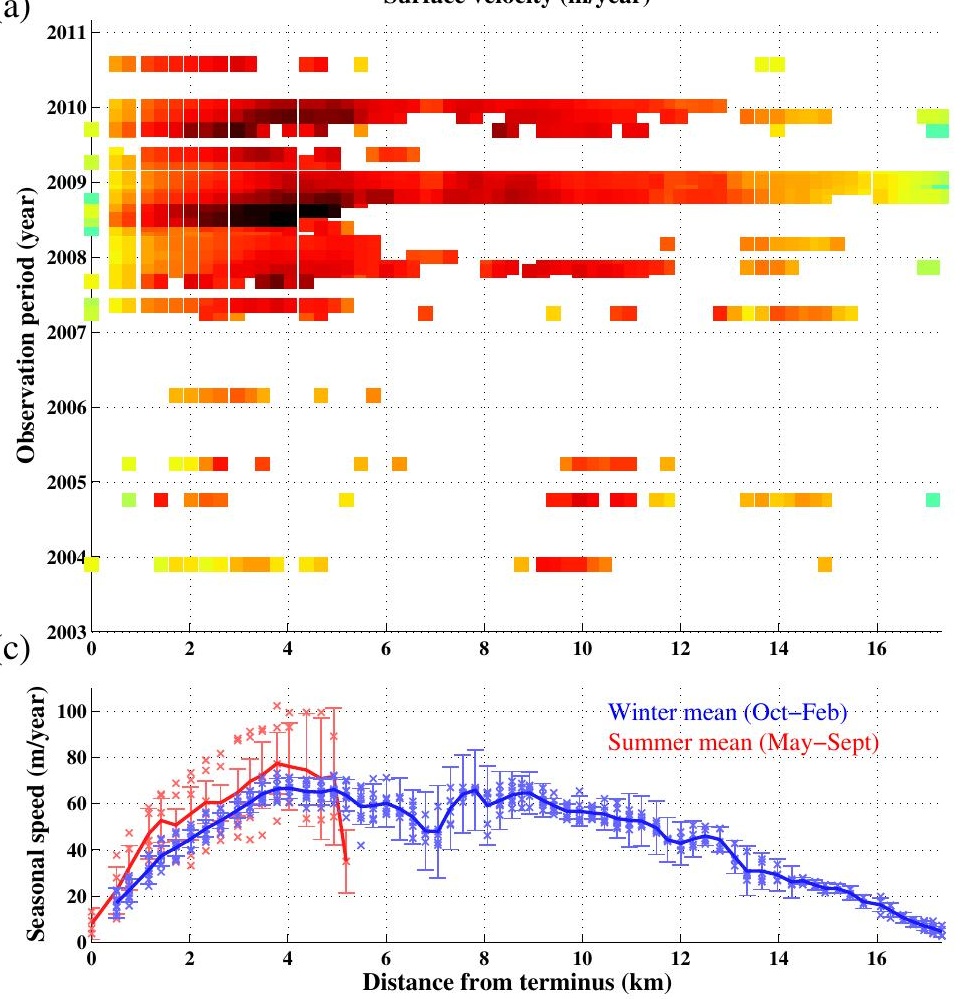

(b)
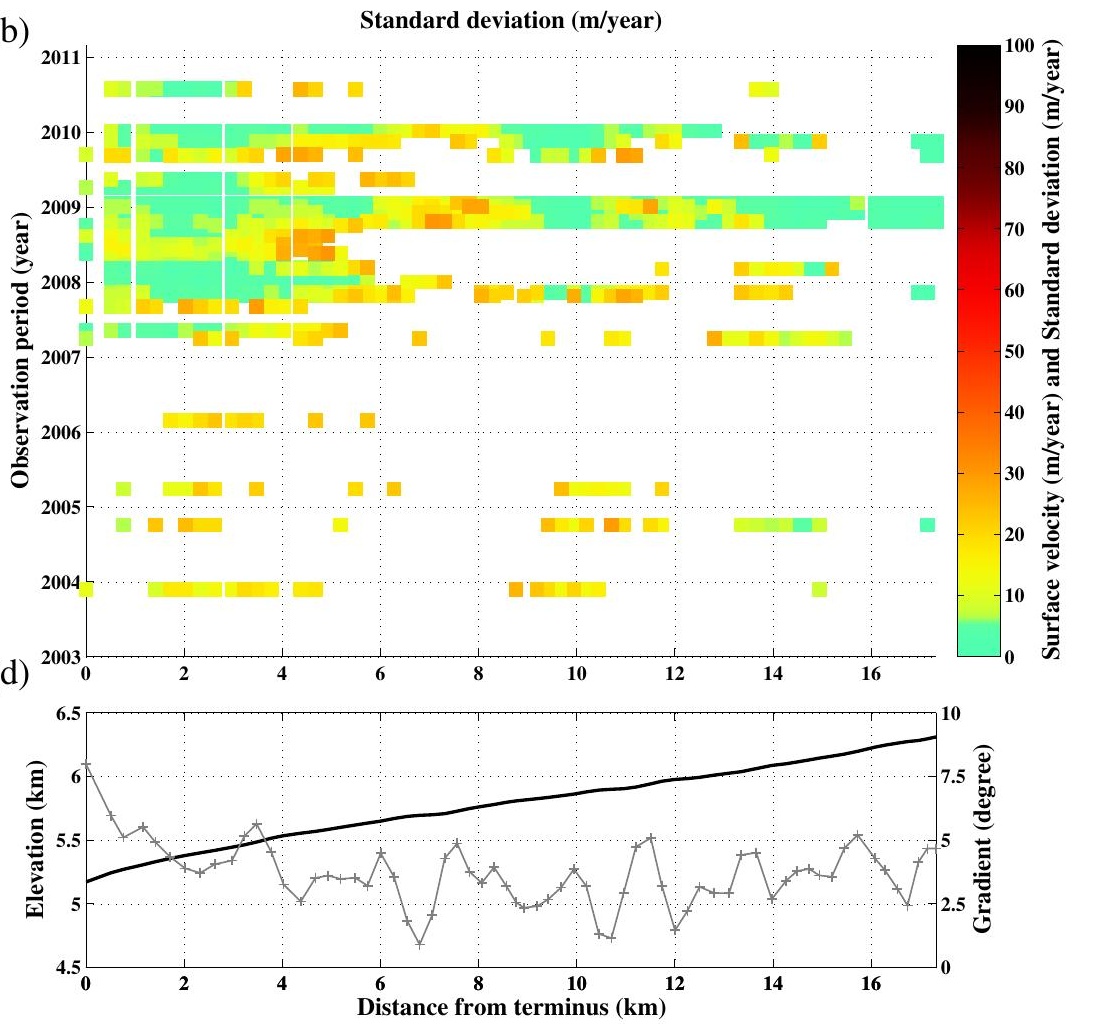
Figure 6

(a)
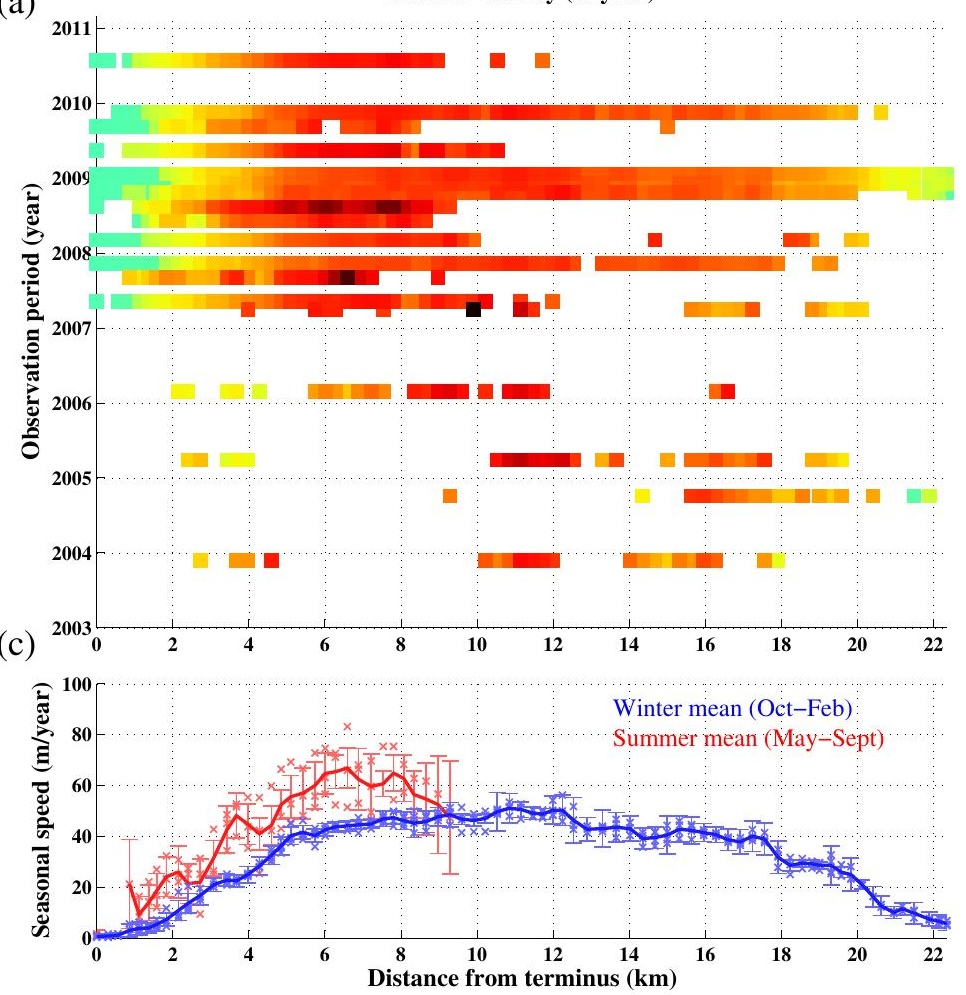

(b)
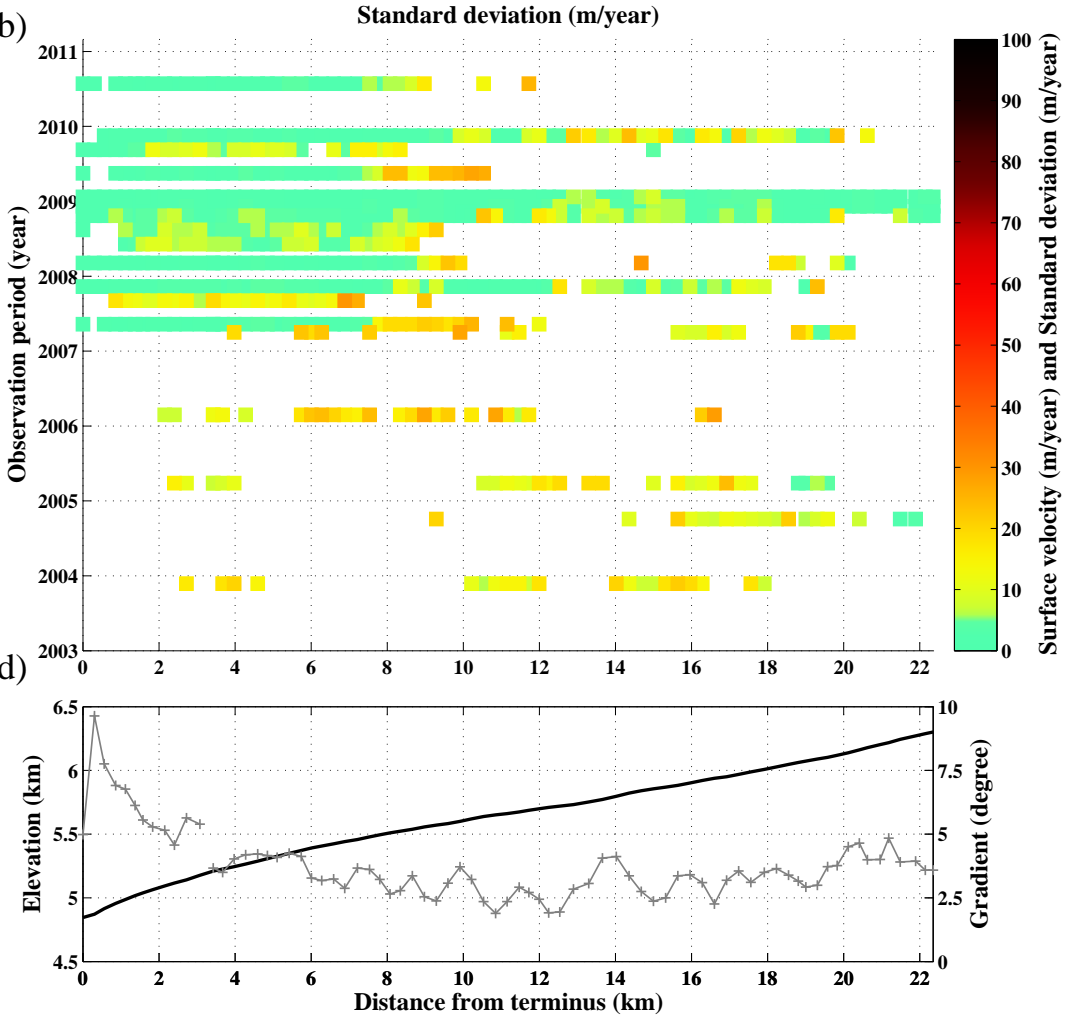
Figure 7

(a)
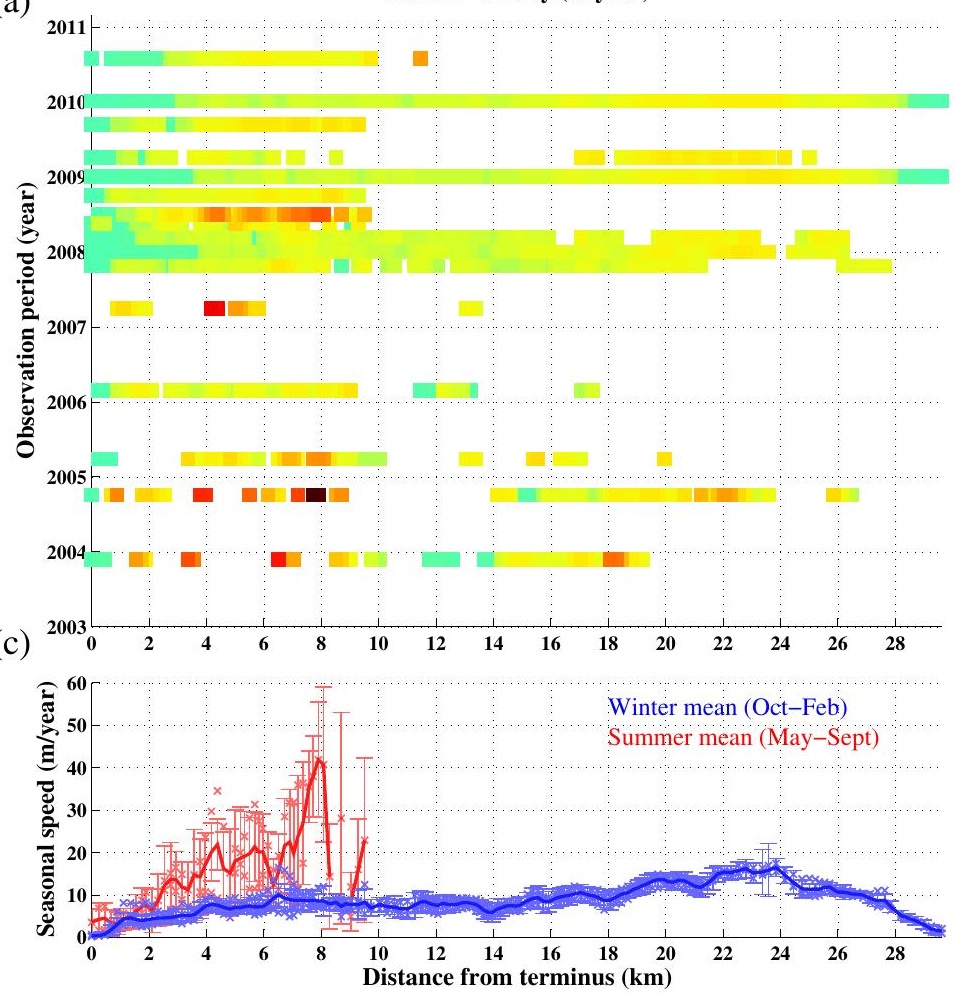

(b)

b) Standard deviation $(\mathrm{m} / \mathrm{year})$
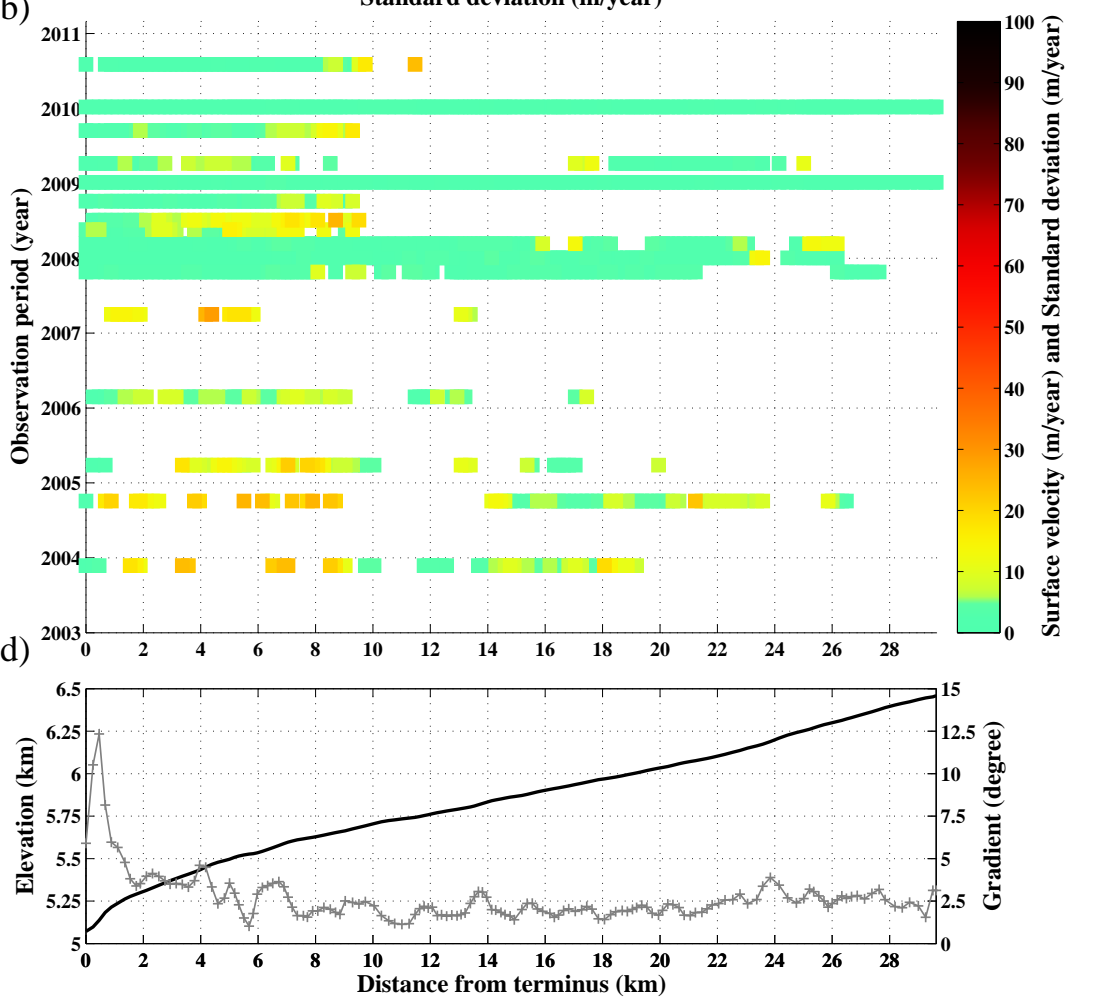
Figure 8

(a)
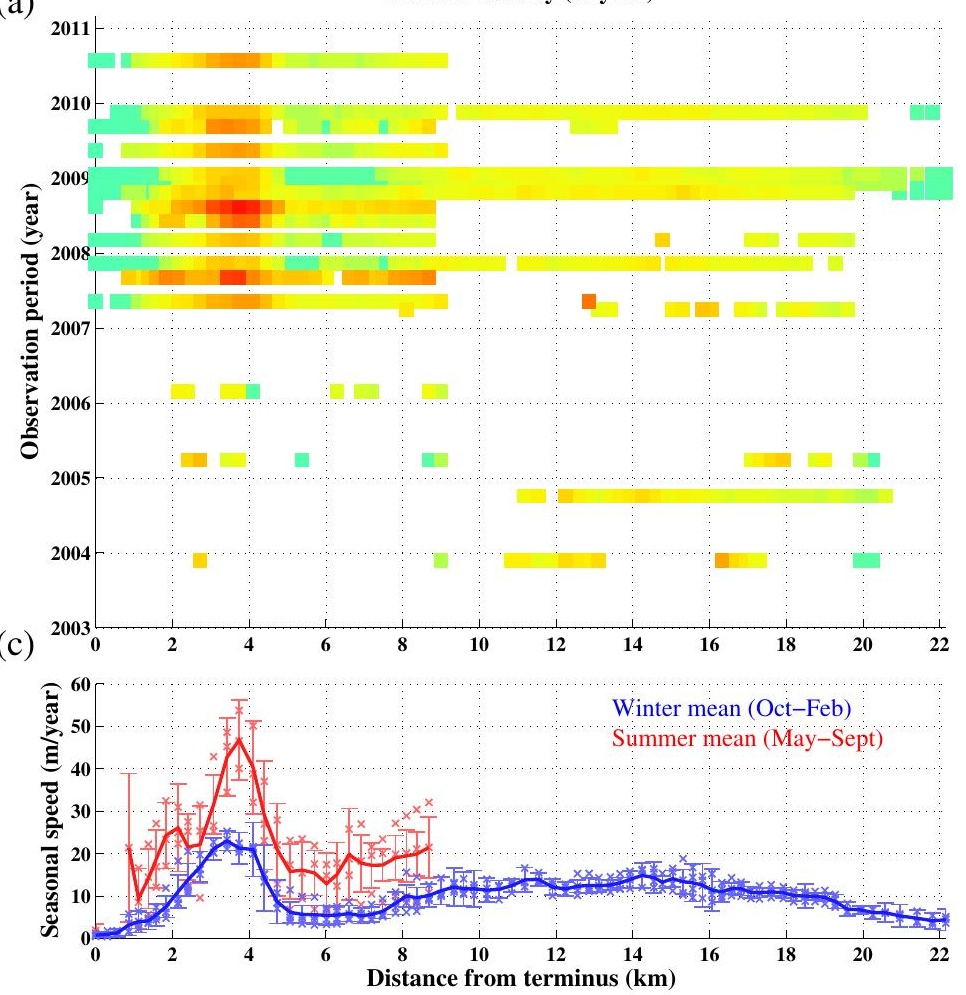

(b)
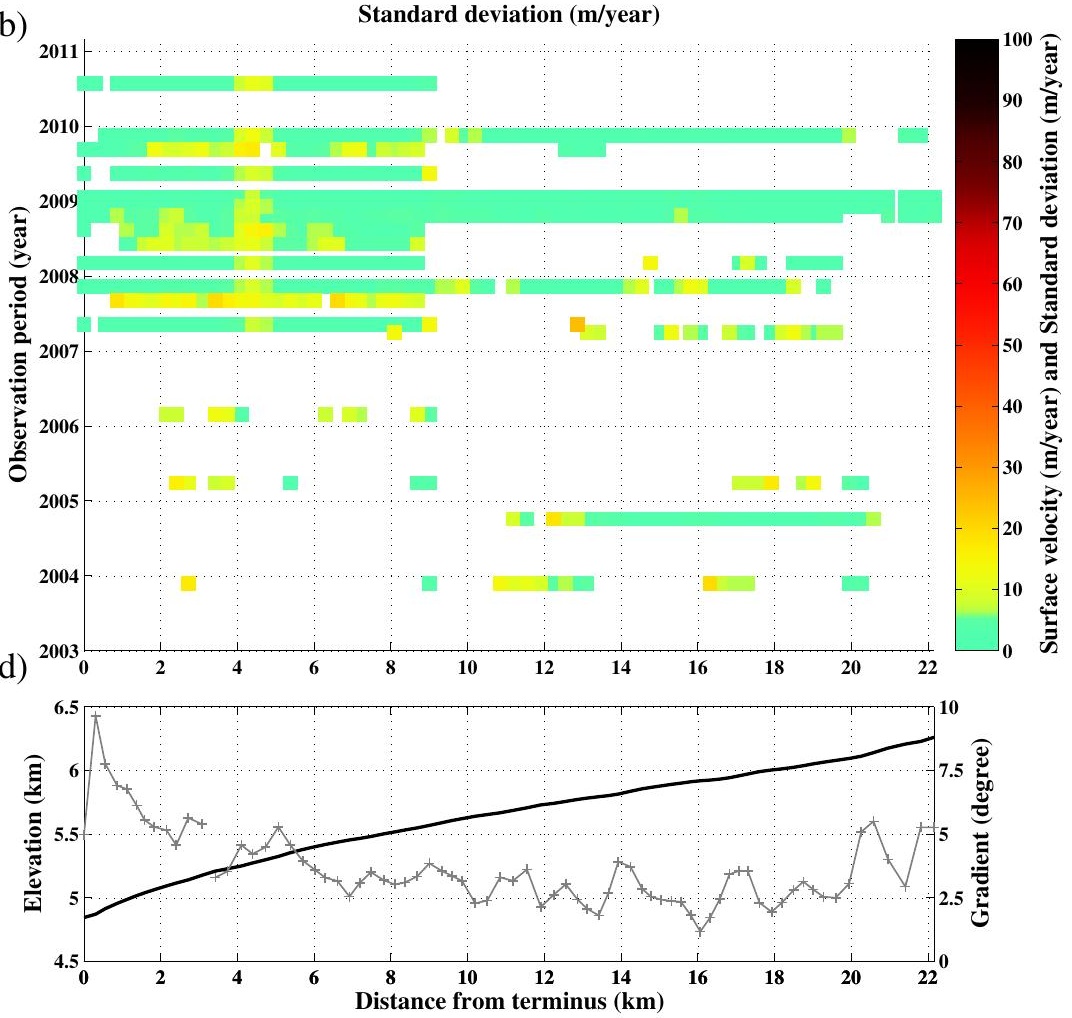
Figure 9

(a)
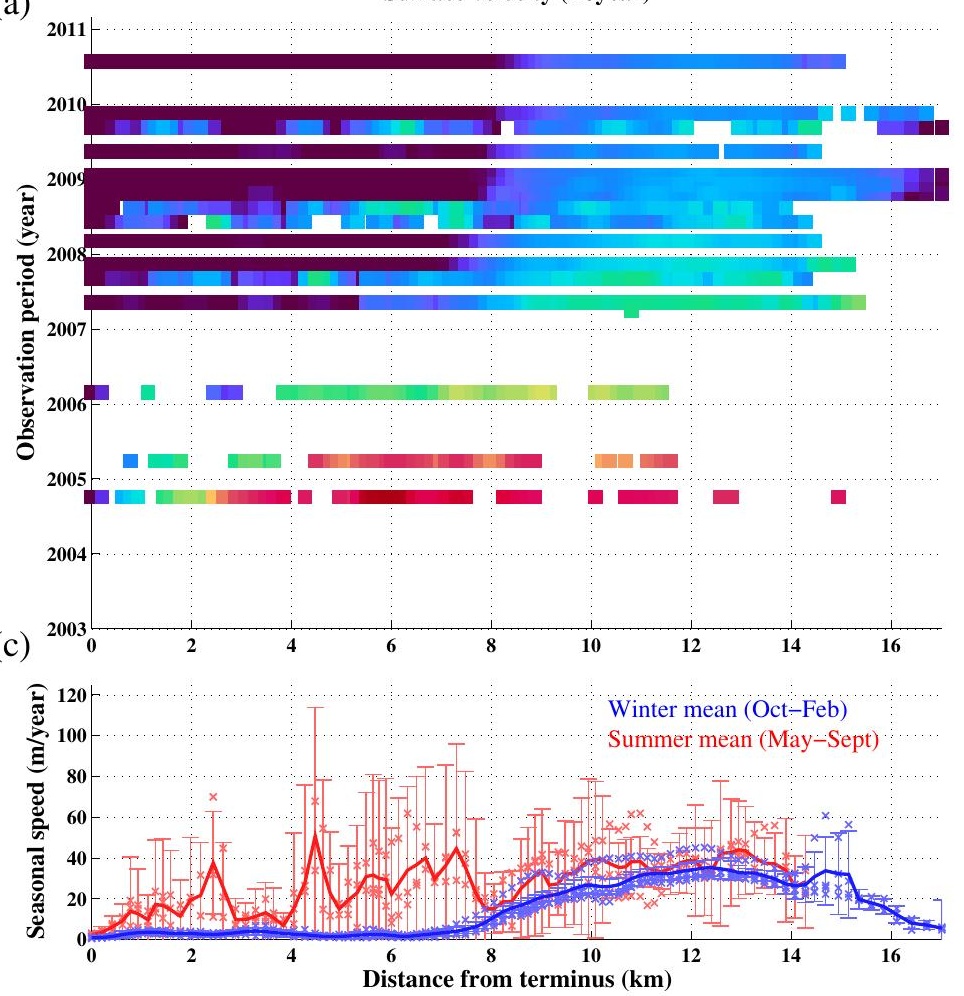

(b)

b)

Standard deviation (m/year)
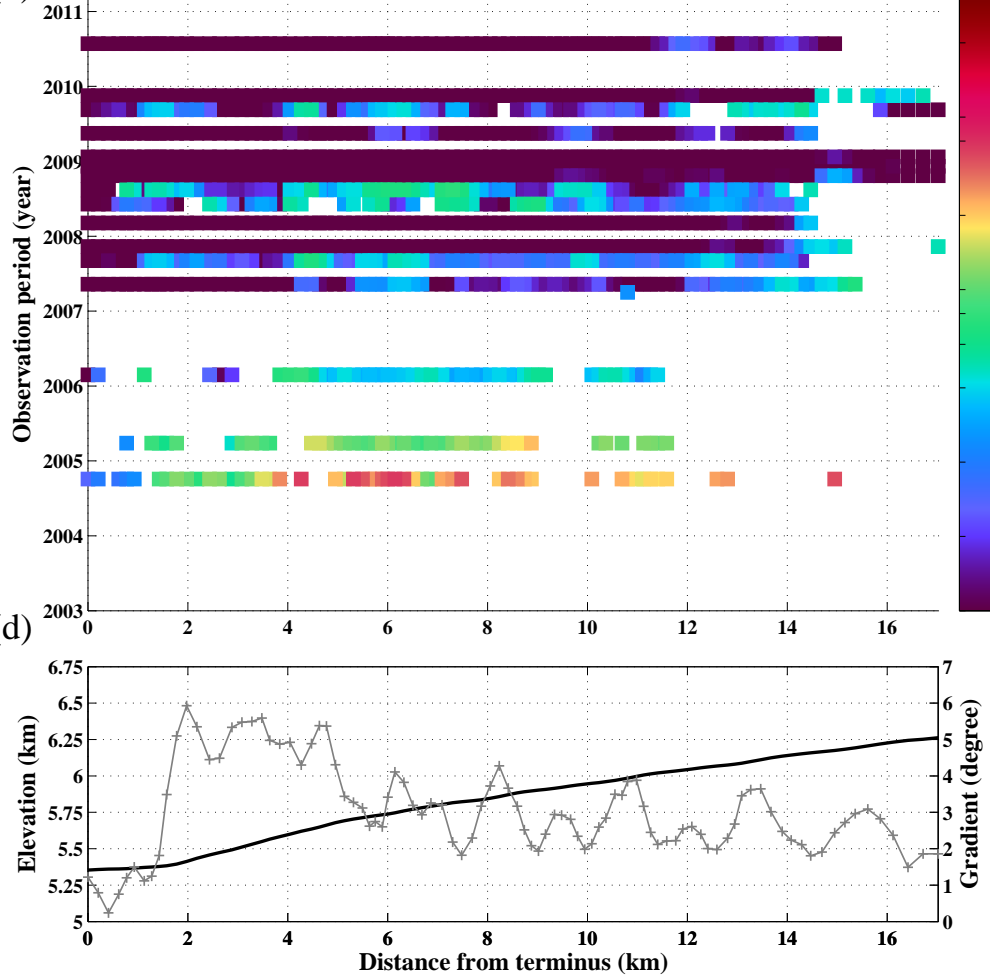
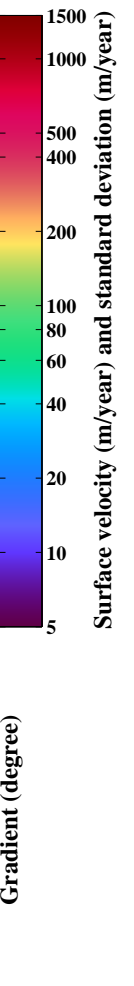


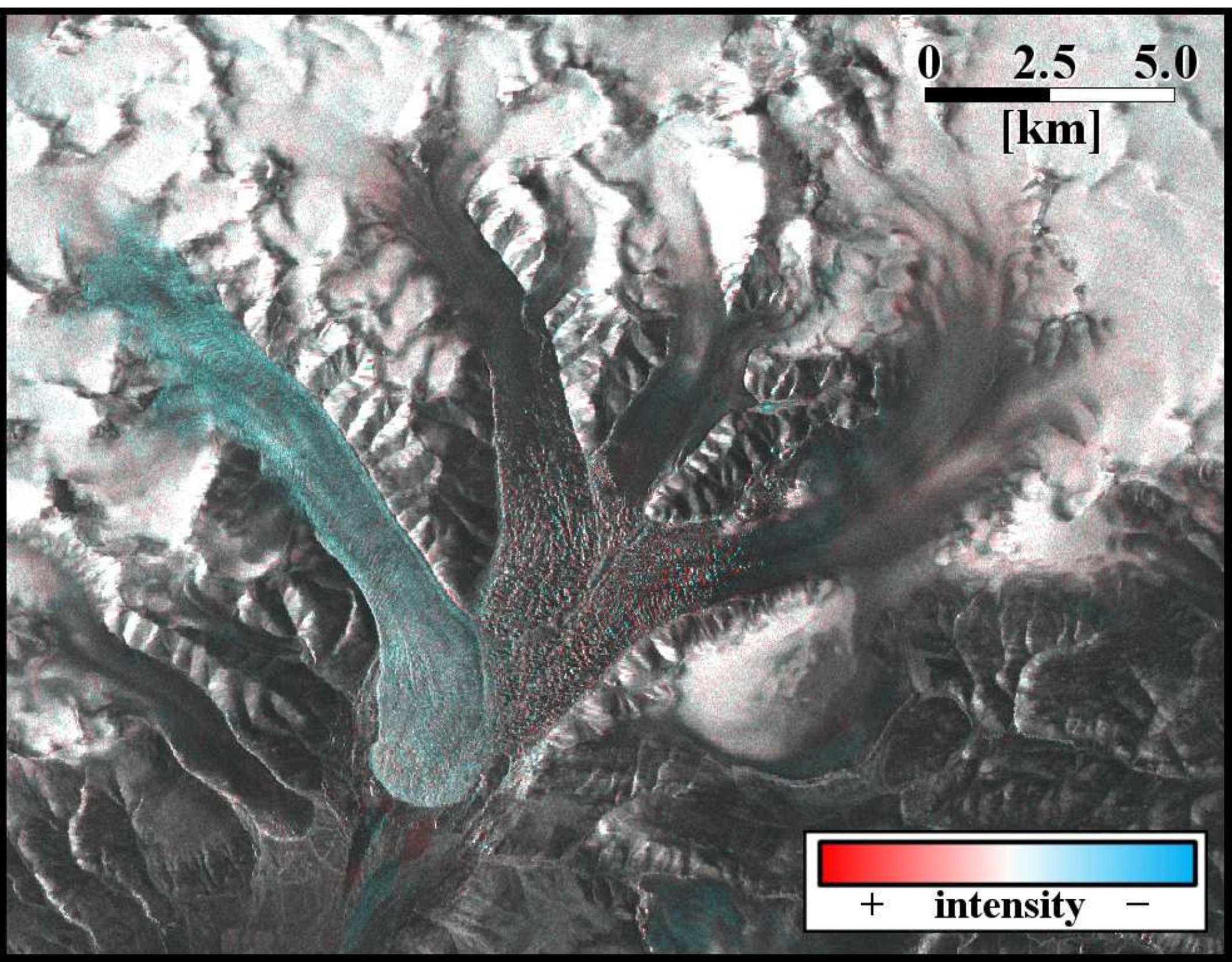


(a)
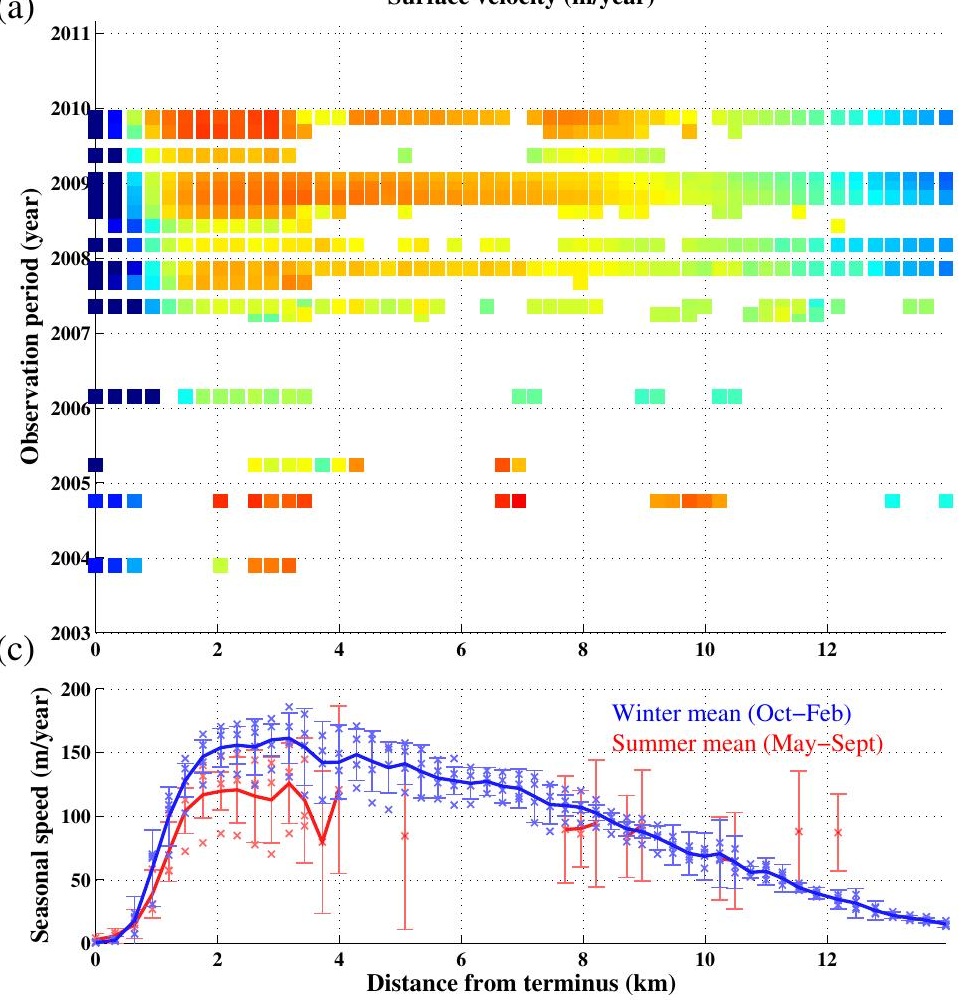

(b)
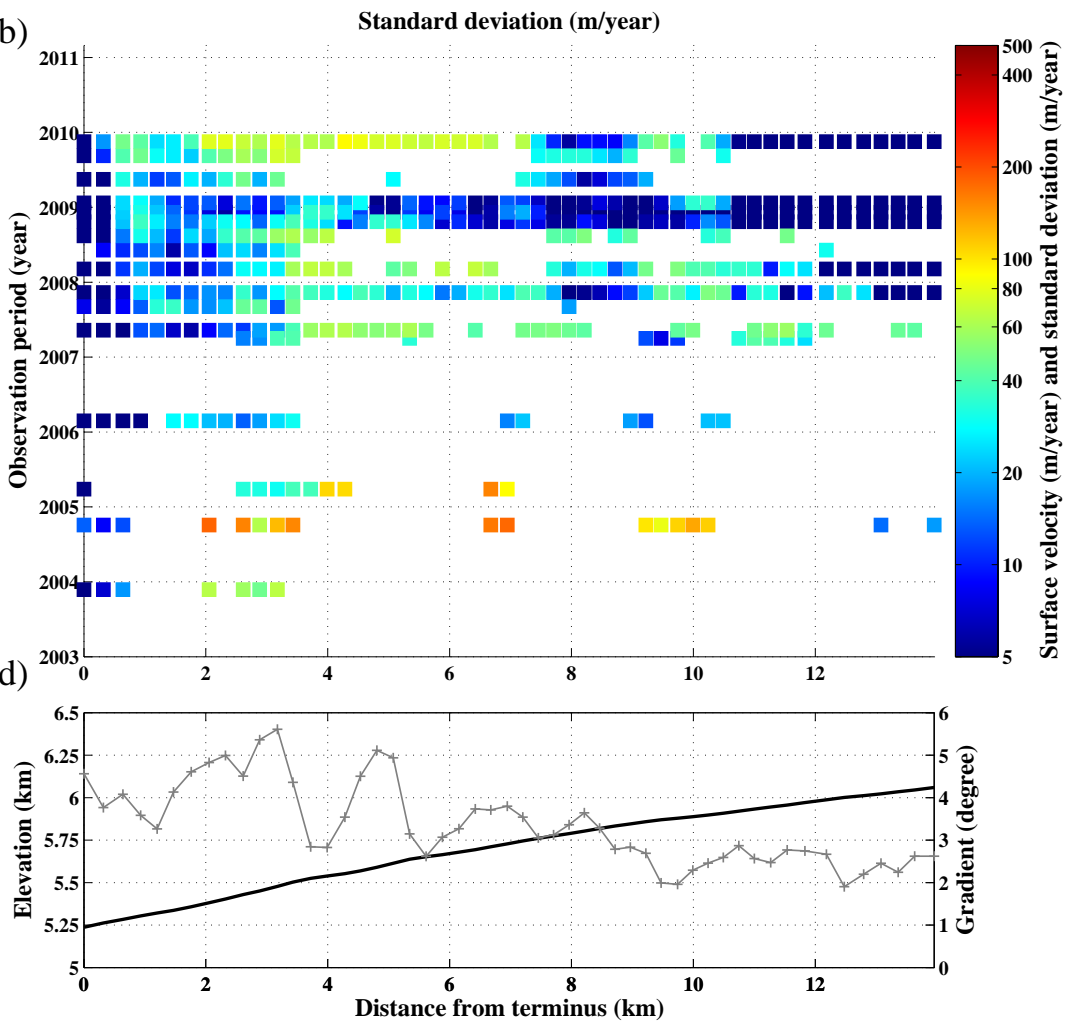
Figure 12

(a)
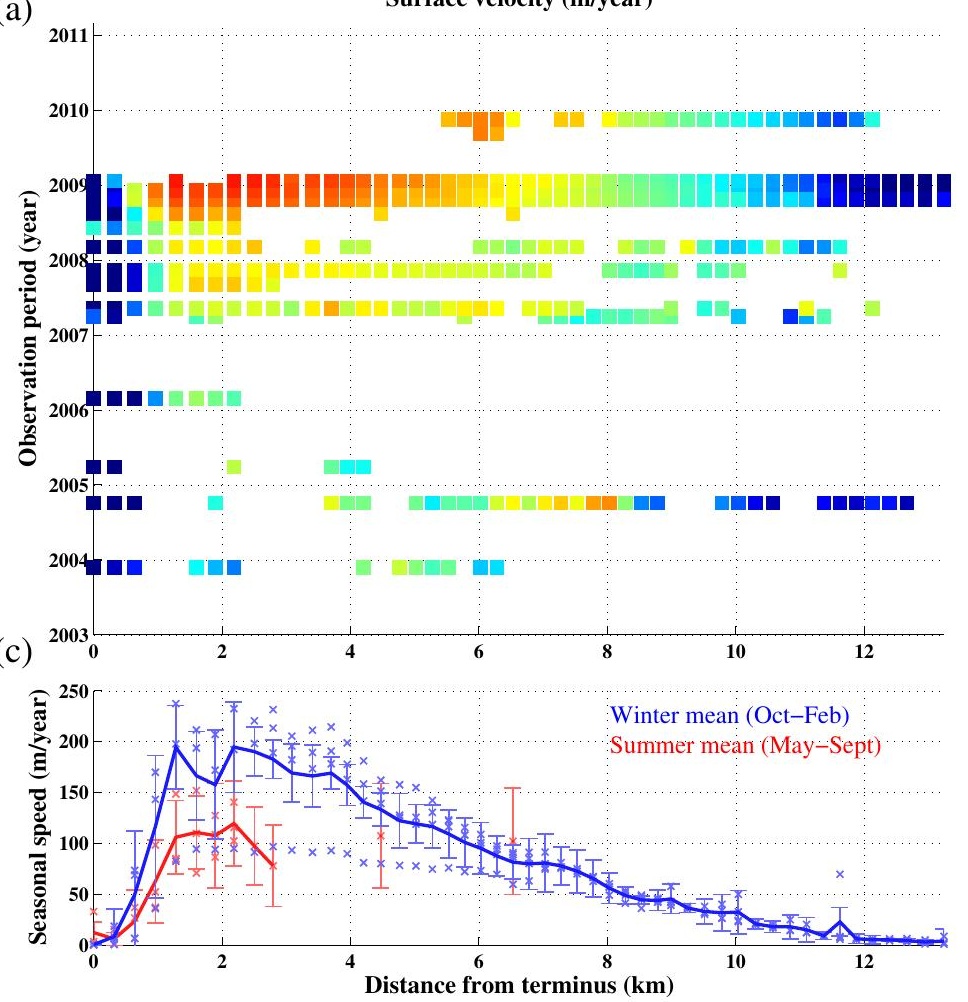

(b)

b) Standard deviation (m/year)
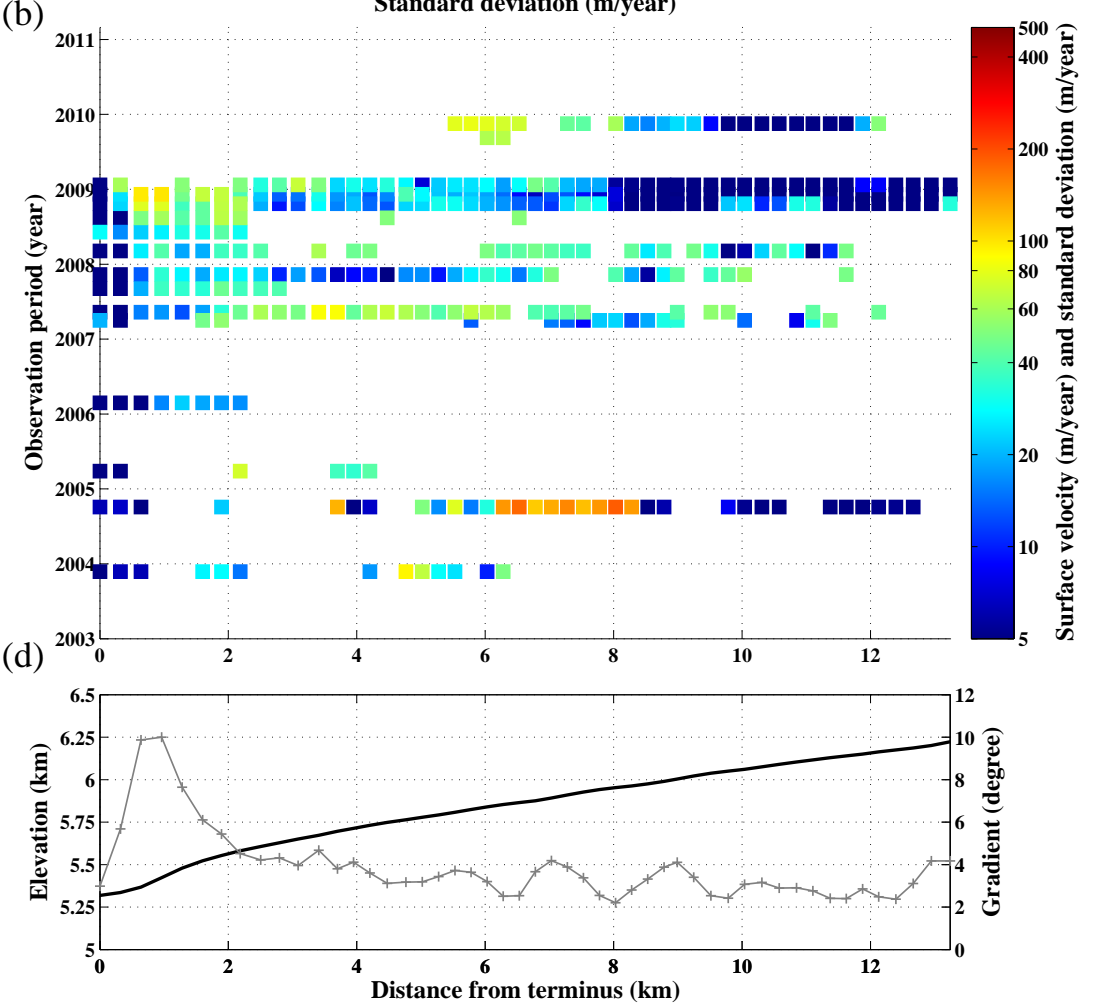


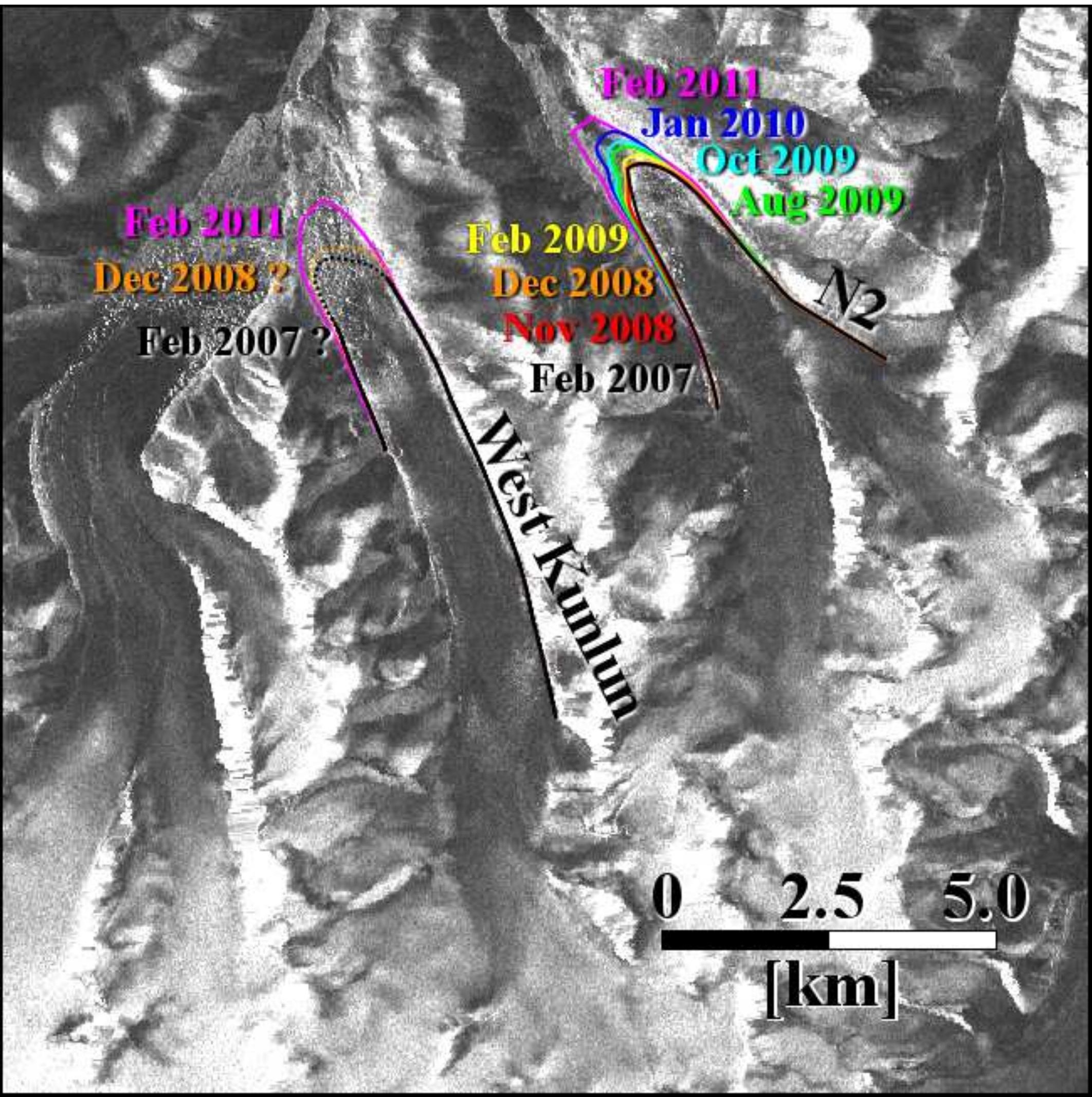

Tebevil a d 2009 $1002007 ?$

5 Feb 2007

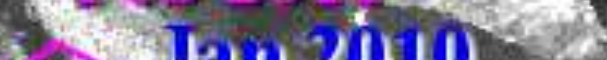
Core01 Nertig 2000 


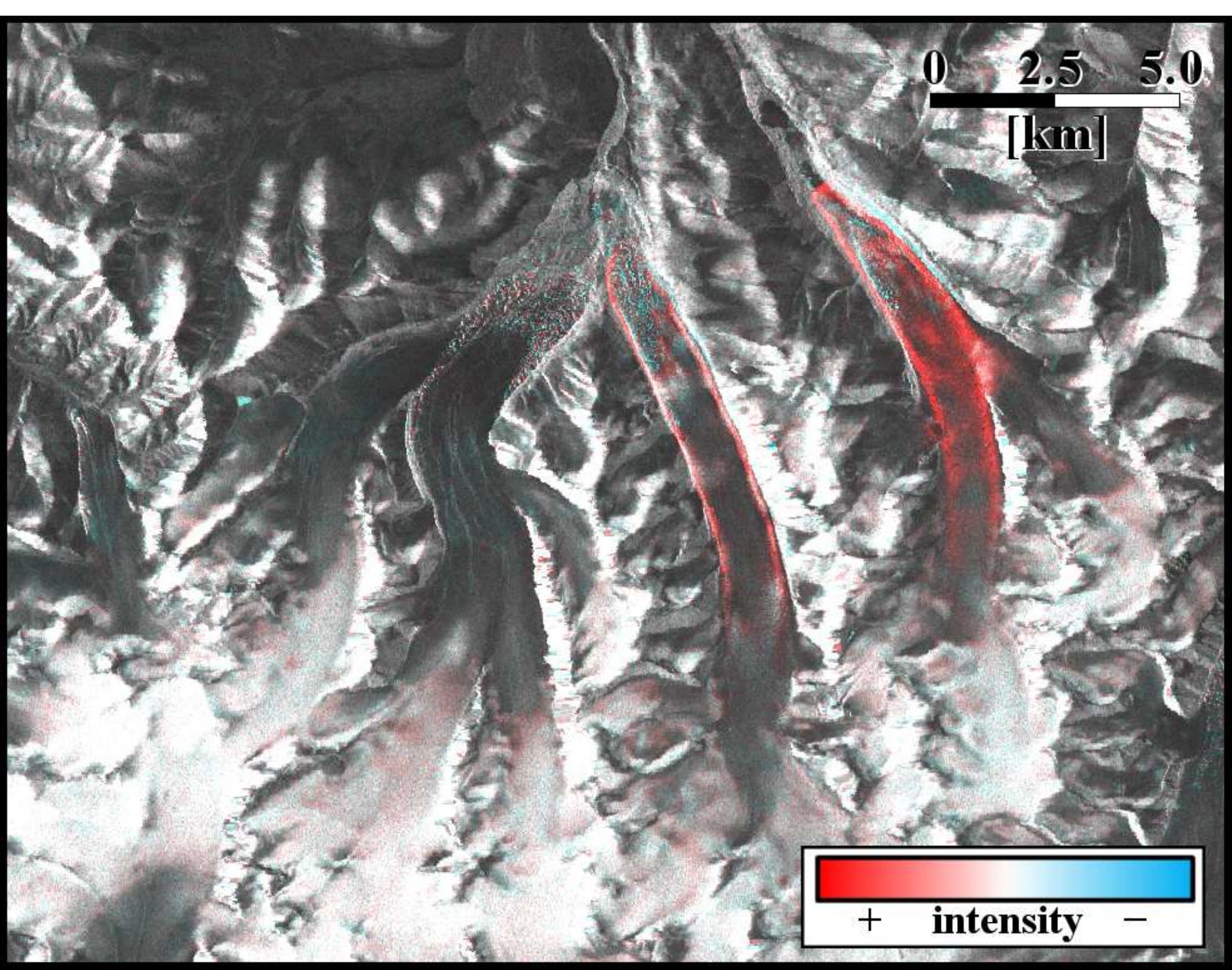

Figure 14

Figure 14

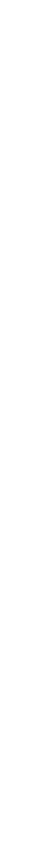


(a)
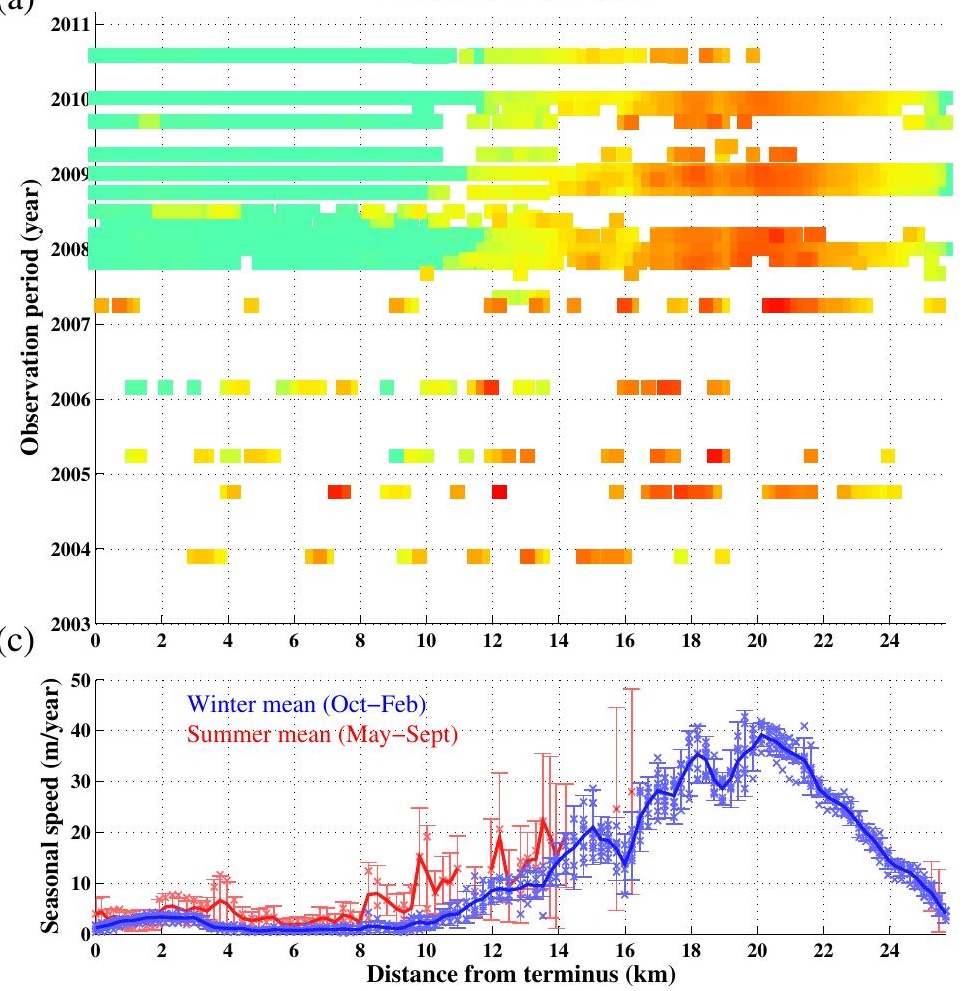

(b)
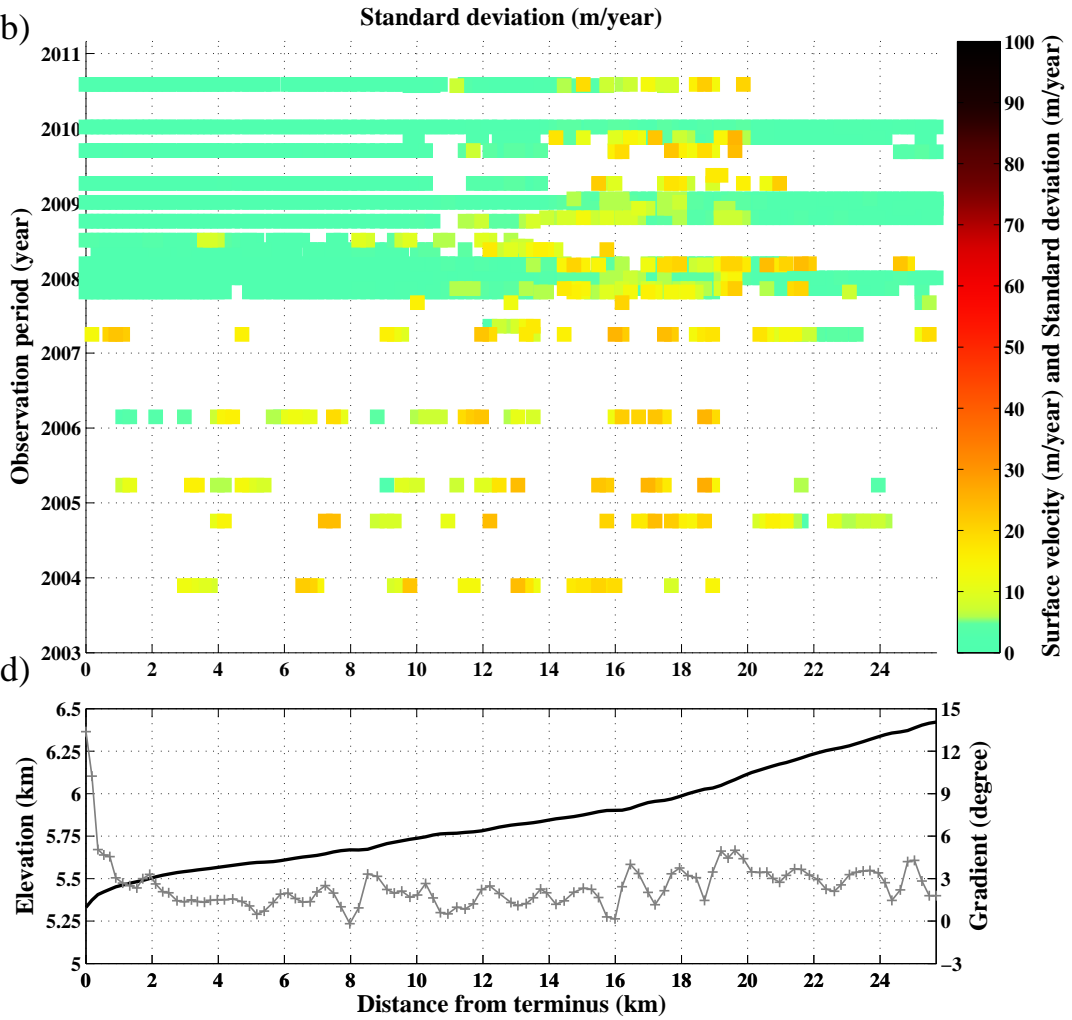
(a)
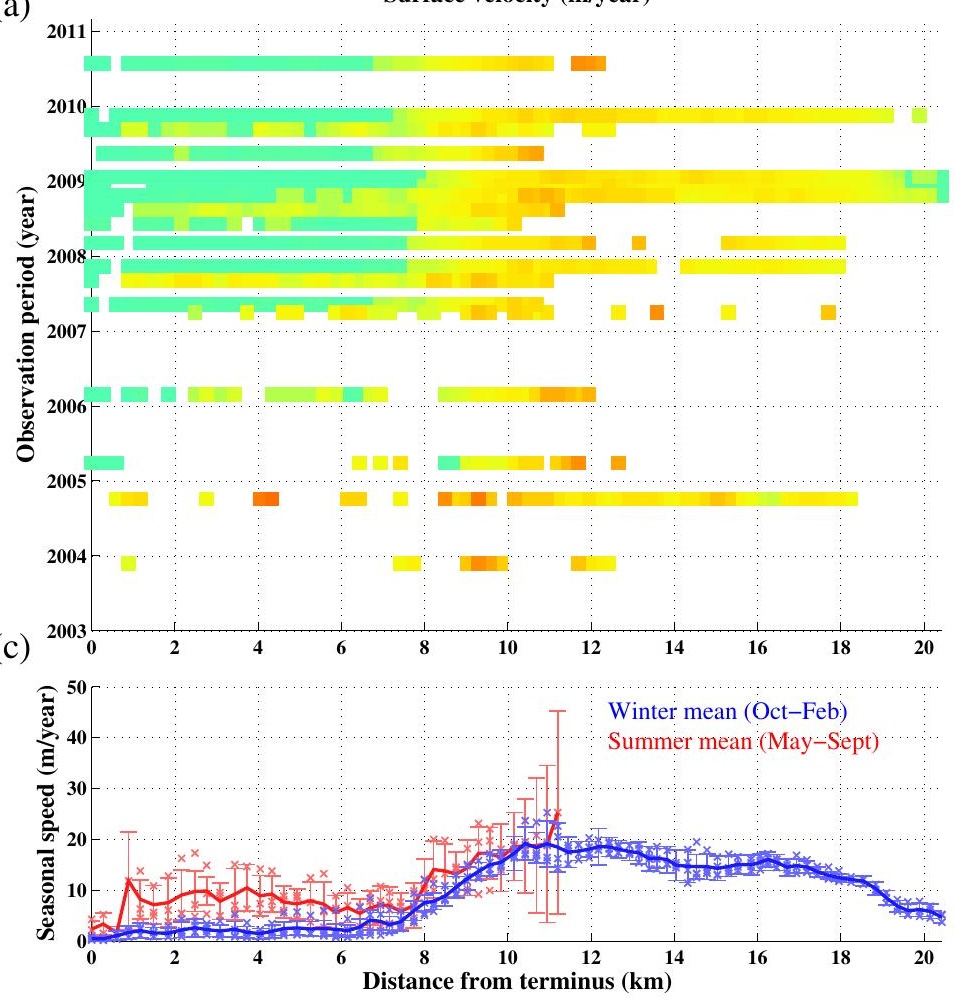

(b)
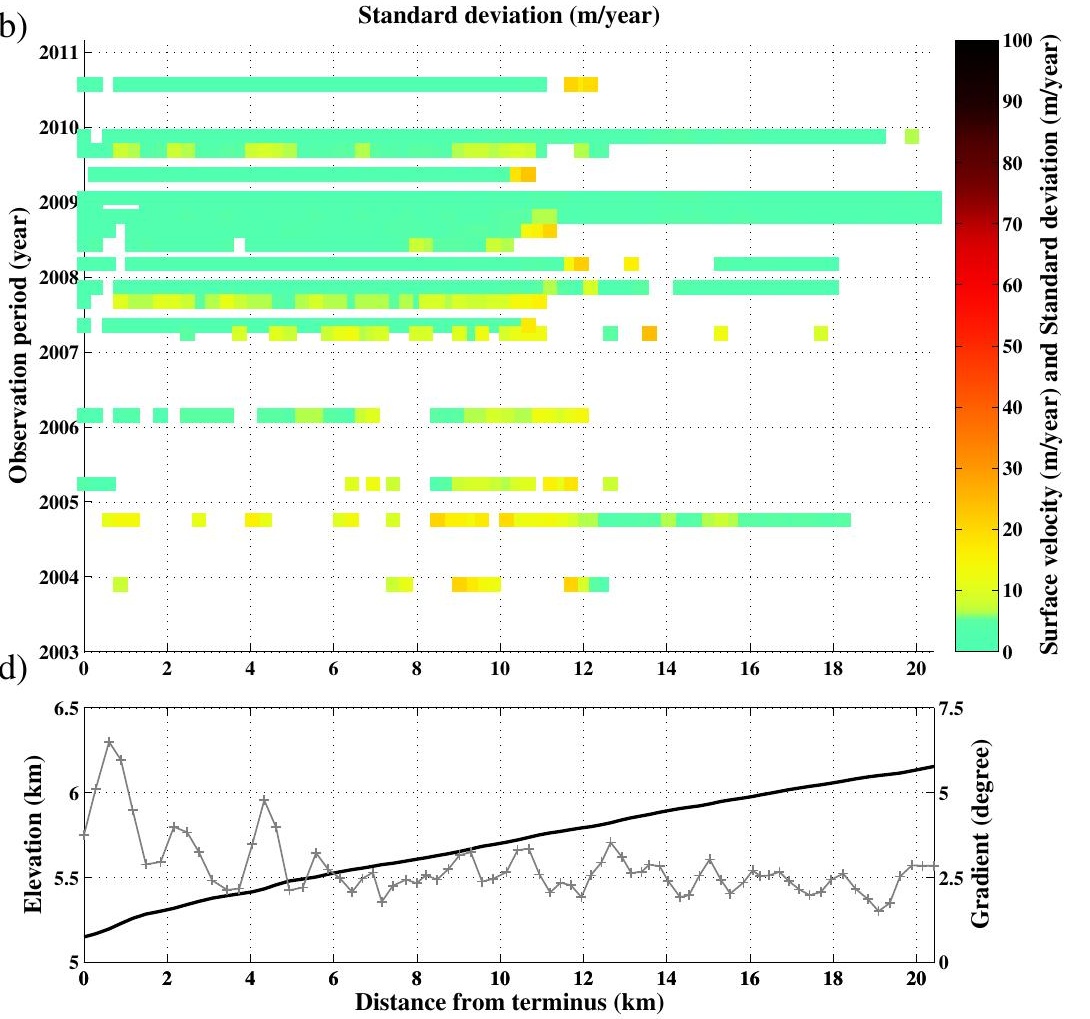
(a)
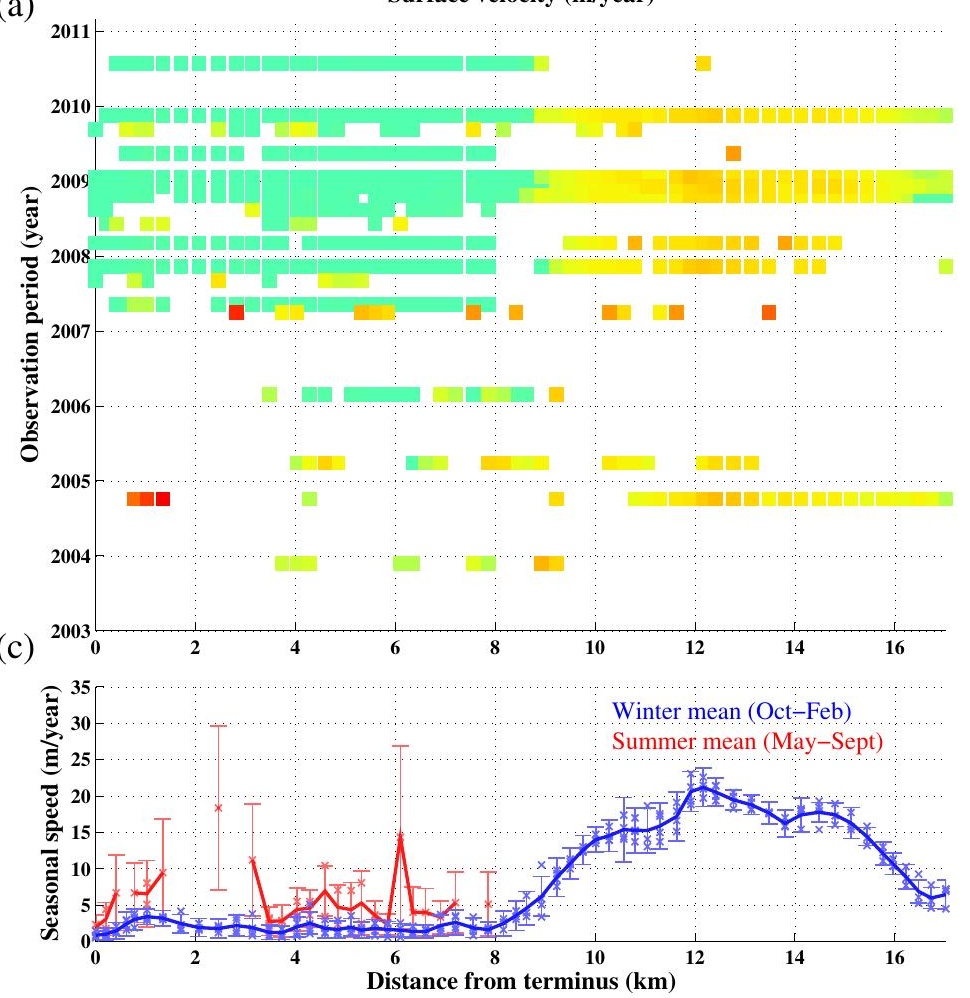

(b)
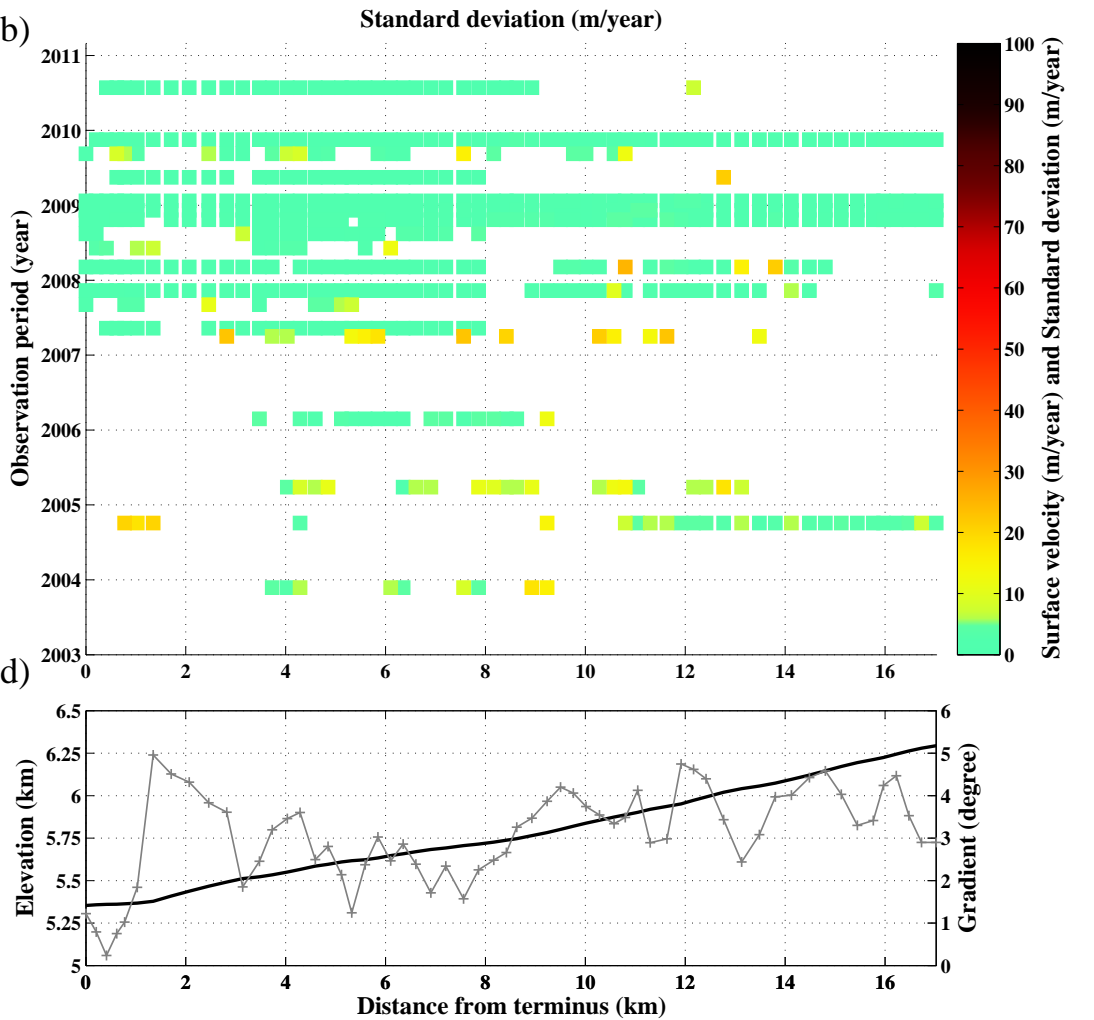